This is an accepted manuscript of an article published by Taylor \& Francis in International Journal of Logistics Research and Applications on 23 Aug 2018, available online:

https://doi.org/10.1080/13675567.2018.1513467

\title{
Short- and Mid-term Evaluation of the Use of Electric Vehicles in Urban Freight Transport Collaborative Networks: A Case Study
}

\author{
Andrés Muñoz-Villamizar ${ }^{1}$ (ORCID: 0000-0003-2542-0645) \\ Carlos L. Quintero-Araújo ${ }^{1}$ (ORCID: 0000-0001-8563-4456) \\ Jairo R. Montoya-Torres ${ }^{2}$ (ORCID: 0000-0002-6251-3667) \\ Javier Faulin ${ }^{3}$ (ORCID: 0000-0002-2613-6155) \\ 1- School of Economics and Management Sciences \\ Universidad de La Sabana \\ Km 7 autopista norte de Bogotá, D.C. \\ Chía (Cundinamarca), COLOMBIA \\ 2- Grupo de investigación en Sistemas Logísticos \\ Facultad de Ingeniería \\ Universidad de La Sabana \\ Km 7 autopista norte de Bogotá, D.C. \\ Chía (Cundinamarca), COLOMBIA \\ 3- Department of Statistics and Operations Research \\ Institute of Smart Cities \\ Public University of Navarra \\ Los Magnolios Blg. First floor, Campus Arrosadia \\ 31006 Pamplona. SPAIN
}

Corresponding author: Jairo R. Montoya-Torres, e-mail: jairo.montoya @unisabana.edu.co

\begin{abstract}
Despite its negative impacts, freight transportation is a primary component of all supply chains. Decision makers have considered diverse strategies, such as Horizontal Collaboration (HC) and the usage of alternative types of vehicles, to reduce overall cost and the related environmental and social impacts. This paper assesses the implementation of an electric fleet of vehicles in urban goods distribution under HC strategy between carriers. A biased randomization based algorithm is used to solve the problem with a multi-objective function to explore the relationships between both delivery and environmental costs. Real data from the city of Bogotá, Colombia are used to validate this approach. Experiments with different costs and demands projections are
\end{abstract}


performed to analyze short- and medium-term impacts related to the usage of electric vehicles in collaborative networks. Results show that the optimal selection of vehicle types depends considerably on the time horizon evaluation and demand variation.

Keywords: Urban Freight Transport; Horizontal Collaboration; Sustainability; Electric Vehicles; Multi-objective Optimization; Case Study.

\section{Introduction}

Transportation plays a very important role in modern society. It is essential for economic development taking into account that globalization has led to an increasing demand for transported goods. Indeed, according to Moore and Pulidindi (2013, p. 5), "economically and socially vibrant urban areas cannot exist without a system for moving people, goods and services. The health of cities, and their ability to generate income and wealth for their inhabitants is improved if the transportation system is efficient". Transportation accounts for $47 \%$ of total transportation of goods in the European Union, 32\% in the USA, and 64\% in Japan (PérezBernabeu et al., 2015). Overall, it is estimated that world freight transport activity will grow up by 82\%, between 2005 and 2050 (European Commission 2011a, b). However, transportation has also negative externalities such as noise, pollution and traffic congestion. Furthermore, transport sector has been largely recognized as a major contributor to climate change. As a matter of fact, in the European Union, road transportation is responsible for the generation of about $82 \%$ of the $\mathrm{CO}_{2}$ emissions and about $18 \%$ of the current Green House Gas (GHG) emissions (Hill et al. 2012), while in the United States of America, in 2013, the transportation end-use sector accounted for a large part of $\mathrm{CO}_{2}, \mathrm{CH}_{4}$ and $\mathrm{N}_{2} \mathrm{O}$ emissions from fossil fuel combustions. Moreover, according to the United Nations (2011), transport activities account for about $25 \%$ of global GHG emissions in the Asia and Pacific region. Among various transportation sources, the light duty vehicles were the main pollutant factor due to the fact they increased by $35 \%$ the distance traveled in the period 1990-2013, causing a $60 \%$ release of $\mathrm{CO}_{2}$ emissions from fossil fuel combustions in 2013 (Nejat et al. 2015). Globally, transportation accounted in 2011 the 22\% of direct $\mathrm{CO}_{2}$ emissions and the $1 \%$ of indirect ones (Nejat et al. 2015). All these factors call for a better planning on transportation activities. However, many efforts for reducing emissions in this sector have not been very successful (Silva and Katz-Gerro, 2016). Within these efforts, transport companies have tried to improve management practices by implementing cleaner technologies in order to increase environmental benefits (or decrease negative externalities).

At the operational decision-making level, goods transportation is one of the most significant components of distribution logistics in supply chain management (Tsao and Lu, 2012). It is hence relevant to continuously enhance planning methods for distribution activities and induce the collaboration of the actors involved by aligning their interests to increase the efficiency of the whole operation. From the optimization point of view, the problem of goods transportation is represented by the Vehicle Routing Problem (VRP). It is indeed the most famous problem regarding transportation planning (Toth and Vigo, 2014). The VRP first appeared in the academic literature with the work of Dantzig and Ramser (1959). Since then, this problem has been widely 
studied by the academic community yielding to different variants inspired from real-life applications (see for example the literature surveys by: (Toth and Vigo 2014, Montoya-Torres et al. 2015, Braekers et al. 2016, Koç et al. 2016, Moons et al. 2016). Nowadays, with the increasing concern on environmental and sustainable development issues in logistics decisionmaking, current research on VRP has focused on the inclusion of environmental issues. This research line is often referred to as the Green Vehicle Routing Problem (GVRP), which is an emerging area of research (Lin et al. 2014). Among the different research directions in GVRP, the search for alternative fuels has led to the introduction of clean energy technologies, such as electricity, ethanol, hydrogen, compressed natural gas, etc. (Erdogan and Miller-Hooks, 2012). The current paper focuses on this direction of the GVRP: using clean energy vehicles.

In addition, because of the globalization of markets, new trends have appeared in the retail industry. Traditionally, transportation organizations (carriers) relied on their internal potential to reduce costs and increase profitability. Most companies, however, have applied optimization techniques to the point where no further improvement of their own processes is attainable. In order to survive under the ever-increasing pressure to operate more efficiently, carriers are obliged to adopt collaborative operations, which opens up cost-saving opportunities that are impossible to achieve with an internal company focus (Ergun et al. 2007; Wang and Kopfer 2011; Vanovermeire and Sörensen 2014). Indeed, environmental concerns and technological innovations in distribution planning and last-mile supply chain management have led decision makers to consider collaborative strategies to reduce overall costs and level of pollution, while improving social management of the supply process. Concerning freight distribution, the most popular collaborative strategy is the sharing of logistics resources (Quintero-Araujo et al., 2017a). This can take place at the transport level, but also in warehousing, inventory and other operations. These strategies are based on collaborative decision-making and information sharing. They usually take the form of agreements and partnerships (Gonzalez-Feliu and Morana 2011).

Among the various possible carrier collaboration strategies, this paper focuses on Horizontal Collaboration (HC). The European Union has defined HC as "concerted practices among companies operating at the same level(s) in the market" (European Union, 2001). These companies can either be competing or unrelated suppliers, manufacturers, retailers, receivers or logistic service providers that share information, facilities or resources with the goal of reducing costs and/or improving service. According to Cruijssen et al. (2007b), HC may be defined as the collaboration between two or more firms that are active at the same level of the supply chain and perform comparable logistic functions. Bahinipati et al. (2009, p. 880) define HC as "a business agreement between two or more companies at the same level in the supply chain or network in order to allow ease of work and co-operation towards achieving a common objective".

Although the main goals of $\mathrm{HC}$ are to reduce shipping costs and to provide a faster distribution service to customers, other important benefits are related to a reduction of the environmental impact of distribution activities (Betkas \& Laporte 2011; Lera-López et al. 2012). In addition, through partnering with fellow transportation organizations, the carriers may extend their resource portfolio, reinforce their market position, enhance their service levels and create a more efficient transport planning (Krajewska and Kopfer 2006; Hernández et al. 2011; van Lier et al. 2016). In summary, the collaboration between actors of goods distribution process has shown to 
have a positive impact when improving the global efficiency and effectiveness of the distribution system (Quintero-Araujo et al. 2017a, b, Muñoz-Villamizar et al. 2017).

Given the previous context, the following research question can be stated: in what extend horizontal collaboration employing a mixed fleet of vehicles (gasoline-based and electric) allows decision makers for an efficient and effective operational planning of freight delivery routes within the context of urban distribution activities? To respond this question, the objective of this paper is threefold. Firstly, a conceptual methodology is applied for the analysis of freight distribution in urban areas in order to evaluate the benefits of horizontal collaboration. The second objective of this paper is a metaheuristic algorithm development, based on biased randomization techniques, taking into account that the collaborative scenario can be modeled as a Multi Depot Vehicle Routing Problem (MDVRP), which is known to be a NP-hard optimization problem (Montoya Torres et al. 2015). Finally, the third objective of this paper is to thoroughly assess the implementation of an electric fleet of vehicles in the urban distribution of goods under $\mathrm{HC}$ strategy, in order to evaluate short- and mid-term environmental impacts. To do so, a multiobjective function is also proposed to explore the relationship between the delivery cost and the environmental impact. The economic cost is calculated using the purchase price of each vehicle, its maintenance cost and the cost of used energy (i.e. gasoline or electricity). The environmental impact is calculated using the $\mathrm{CO}_{2}$ emissions created by the production of the energy and the emissions created by the consumption of the energy during transportation. In addition, we consider the different characteristics of the available vehicle types (e.g. power source, autonomy, $\mathrm{CO}_{2}$ emissions, capacities, etc.)

This approach is validated using real-data taken from the city of Bogotá, Colombia. Experiments with different costs and demands projections are performed as well as to analyze short- and medium-term impacts related to the use of electric vehicles in the configuration of the collaborative transport network.

This paper is organized as follows. Section 2 presents a review of related literature. The problem under study is formally described in Section 3. Section 4 is devoted to describing the proposed solution approach, including the characterization of the problem under study and the algorithm employed to solve this hard optimization problem. Experiments and analysis of results are presented in Section 5. The paper ends in Section 6 by presenting some concluding remark and highlighting some opportunities for further research.

\section{Literature review}

\subsection{Horizontal collaboration $(H C)$ in transportation}

According to Gonzalez-Feliu et al. (2013), over recent years, several strategies and logistic models have been developed in order to increase supply chain efficiency, where collaboration is one of the most promising areas of study in supply chain management. In the academic literature, collaboration is commonly seen all along the supply chains (Montoya-Torres and Ortiz-Vargas, 2014). In general, two types of collaboration can be distinguished: between actors in a supply chain at different stages (vertical collaboration) and between actors of the supply chain at the 
same level having analogous needs (horizontal collaboration) (Gonzalez-Feliu et al. 2013). This collaboration in urban logistics can take place at several stages and can involve different levels of interaction: transactional, informational, and decisional (Lambert et al. 1999, Gonzalez-Feliu and Morana 2011). Various types of horizontal collaboration have been discussed in both professional and academic literature. Cooperation, collaboration, alliances, and partnerships are all used to refer to concerted practices on horizontal supply chain links (Cruijssen et al. 2007b). However, collaboration involves much more than cooperation, especially in terms of sharing information, risks, knowledge, profits, etc.

In most of the cases, the HC literature focuses on alliances in which customer requests are exchanged between the participating organizations through various techniques (Verdonck et al. 2013). A mechanism generally accepted in HC contexts is the joint route planning concept, which assumes that the customer orders from the consortium members are combined and collected in a central pool. Moreover, the efficient route schemes are set up for all requests using appropriate vehicle routing techniques. Under some general circumstances, HC in urban freight delivery can be modeled as a Multi-Depot Vehicle Routing Problem (MDVRP) (Quintero-Araujo, 2017; Perez-Bernabeu et al., 2015). In this way, economies of scale can be obtained (Cruijssen and Salomon 2004, Cruijssen et al. 2007a,b). Indeed, companies are incentivized to share trucks, routes and costumers in order to improve their individual turnovers. Similarly, they offer, in many cases, a better service to customers, along with reducing the environmental impact of the delivery activities (Muñoz-Villamizar et al. 2015).

Caputo and Mininno (1996) presented one of the first works enhancing HC describing the main activities which support it: electronic documents use, standardized containers and pallets design, multi-supplier warehouses selection, coordinated routing plans implementation and load consolidation in the delivery processes. More recently, Krajewska et al. (2008) analyzed different ways to redistribute profit margins of freight carriers involved in HC alliances. Cruijssen and Salomon (2004) studied how the shared information among carriers can lead to savings between 5\% and 15\% due to improved transport planning, while Leitner et al. (2011) identified planning premises to favor HC organizational models in logistics.

At the operational level, most published works applied to logistics field are related to maritime and air transport (where major alliances between airlines can be easily found), while research on $\mathrm{HC}$ in road transportation is scarce, despite the advantages that can be achieved. Indeed, HC between carriers allows the reduction of return trips without cargo. In Europe, empty returning trips account for about 25\% of road transportation activities (European Commission 2011c), while backhaul trips in China account for almost the half of the traveled distance (Punte 2011). Several research works showing the benefits of $\mathrm{HC}$ employing different measures, frameworks, optimization and/or simulation models (see Table 1). In addition to backhauling routing, those works also address different objective functions and approaches, such as the reduction of $\mathrm{CO}_{2}$ emissions, total distance traveled, number of routes and the utilization level of vehicles. 
Table 1. Characteristics of sample works in $\mathrm{HC}$

\begin{tabular}{lcc}
\hline \multicolumn{1}{c}{ Authors } & $\begin{array}{c}\text { Proposed } \\
\text { considerations }\end{array}$ & Objective function / Metric \\
\hline Cruijssen and Salomon (2004) & Order sharing & Cost minimization \\
Nadarajah (2008) & Goods exchanging & Distance minimization \\
Prakahs and Deshmukh (2010) & $\begin{array}{c}\text { Simulation of flexible } \\
\text { supply chains }\end{array}$ & $\begin{array}{c}\text { Total cost(ordering cost, } \\
\text { inventory cost and back order } \\
\text { cost) }\end{array}$ \\
Bailey et al. (2011) & Backhaul Costs & $\begin{array}{c}\text { Collaborative savings } \\
\text { maximization }\end{array}$ \\
Anand and Bahinipati (2012) & $\begin{array}{c}\text { Compatibility among } \\
\text { competing suppliers } \\
\text { Transshipment in } \\
\text { pickup and delivery } \\
\text { problem }\end{array}$ & $\begin{array}{c}\text { Horizontal collaboration } \\
\text { intensity metric }\end{array}$ \\
Pérez-Bernabeu et al. (2015) & $\begin{array}{c}\text { Greenhouse gas } \\
\text { emissions }\end{array}$ & Distance minimization \\
Montoya-Torres et al. (2016) & City logistics & Cost minimization \\
Quintero-Araujo et al. (2017a) & $\begin{array}{c}\text { Integrated Routing and } \\
\text { Facility Location } \\
\text { Decisions }\end{array}$ & Costs minimization \\
Quintero-Araujo et al. (2017b) & Stochastic demand & Distance minimization
\end{tabular}

\subsection{Vehicle routing using electric vehicles}

As pointed out before, the Vehicle Routing Problem (VRP) is a central problem in transportation (Bektaş et al. 2016). The standard objective function for traditional VRP is to minimize the total traveling distance, while many of the Green VRP (GVRP) papers consider the reduction of pollutants, such as nitrogen oxides $\left(\mathrm{N}_{2} \mathrm{O}\right)$ (Jovanović, 2014), particulate matters (Ćirović, 2014) and greenhouse gases (GHG) (Madankumar and Rajendran, 2015). Some papers directly add those items into the objective function, while many others consider fuel consumption as a relative concept (Demir et al. 2014b), because it can be sometimes used as a surrogate measure for the emissions of air pollutants. The simultaneous consideration of economic and environmental objectives leads to more complex optimization problems.

Also, as pointed out before, collaborative transport network configuration can be performed through solving the variant of the VRP known as Multi Depot Vehicle Routing ProblemMDVRP. In terms of the computational complexity, the MDVRP is known to be NP-hard, which means that exact solution methods can provide optimal solutions only for small datasets. Therefore, heuristics and metaheuristics methods have been developed to provide near-optimal solutions for mid- to large-sized instances or to real-life cases (Quintero-Araujo et al., 2017a). 
Furthermore, an important characteristic of real-life logistics problems found in enterprises is that decision-makers, very often, have to simultaneously deal with multiple objectives. These objectives are sometimes contradictory (e.g. minimizing number of vehicles and maximizing service level). As pointed out by Pérez-Bernabeu et al. (2015), very few papers have discussed $\mathrm{HC}$ through multi-objective / multi-criteria decision-making models. There are very few papers in the literature on the MDVRP that consider multiple objectives (Montoya-Torres et al., 2015).

Furthermore, the use of electric vehicles in the context of GVRP represents a promising opportunity for reducing costs and pollution caused by transportation. Despite the fact that some limitations, such as high costs, have hampered their diffusion, there is continuous technological progress to improve them (Felipe et al., 2014; Feng and Figliozzi, 2012). As pointed out by Arslan et al. (2015), the usage of electric vehicles in the logistic operations led to several new problems flourishing in the literature such as pollution-routing problem (Bektas and Laporte, 2011; Demir et al., 2014a; Franceschetti et al., 2013; Koç et al., 2014), green-vehicle routing problem (Erdogan and Miller-Hooks, 2012; Cirovic et al., 2014; Felipe et al., 2014; Jabir et al., 2015), location optimization of alternative fuel stations (Yildiz et al., 2015), and mixed-fleet routing problems (Schneider et al., 2014; Goeke and Schneider, 2015). These studies establish the environmental and operational impacts of electric vehicles from the logistics perspective. As pointed out by Lin et al. (2014), GVRP has recently arisen in the literature with a continuing need of enriching the related studies either through theoretical contributions or by real applications.

\subsection{Summary}

Goods transport is essential for the economic growth of cities and regions (Lin et al., 2014). In order to reduce the negative externalities of transportation systems, several strategies have been implemented, such as $\mathrm{HC}$ and the use of alternative fuel vehicles (such as electric vehicles). The evaluation of $\mathrm{HC}$ strategies among carriers allows the reduction of vehicle empty trips, and hence reduces $\mathrm{CO}_{2}$ emissions, total distance traveled, number of routes and increases the utilization level of vehicles. Nevertheless, the inclusion of pollutant emissions in vehicle routing problems has allowed the design of new routing models and the development of new optimization algorithms (Bektas and Laporte 2011). Currently, logistics and transportation systems include heterogeneous fleets for their activities. These mixed fleets consist of common internal combustion engine vehicles as well as other vehicles using sustainable technologies, (e.g. electric vehicles). The incorporation of a mixed-fleet of vehicles in transport systems activities also raises some additional challenges from the strategic, planning, and operational perspectives (Juan et al. 2016).

To the best of our knowledge, no previous work discusses the impact of the electric vehicles use in collaborative urban transport networks considering multiple objectives on both short and medium terms. The problem under study in this paper seeks addressing these issues: horizontal collaboration with electric vehicles, and thoroughly measuring their economic and environmental impacts. The proposed approach is modeled using metaheuristic procedures based on biased randomization techniques. 


\section{Problem description}

Traditionally, goods distribution has been considered from an individual perspective. That is, each company decides from which logistics facility (depot, warehouse, distribution center, etc.) its customers will be served. This situation can be easily modeled by the well-known Capacitated Vehicle Routing Problem (CVRP). In the case of different companies serving the same area, the situation becomes a set of individual Capacitated Vehicle Routing Problems (CVRPs) (MuñozVillamizar et al. 2017). The CVRP model designs delivery routes, each of them covered by a single vehicle starting and finishing at the central depot. Each customer is visited once and all vehicles have the same characteristics. The aim of the CVRP is to find a set of routes that minimizes total costs. Vehicles' capacities must be respected while customers' demands are to be satisfied. However, in recent years, different business strategies have appeared trying to overcome such individualized approach. In that sense, HC can be implemented between companies in order to better achieve their goals while reducing operational costs, among other benefits (Quintero-Araujo et al. 2017a). An example of HC occurs when different companies decide to cooperate by sharing both depots and vehicles capacities, to perform the final delivery to their customers. In this case, it is assumed that each company has already determined the logistics facility from which it serves its customers. As mentioned before, this situation can be modeled by the Multi Depot Vehicle Routing Problem (MDVRP). The main objective of a MDVRP is to find the customer allocation to facilities and the corresponding routes to serve all customers' demands while minimizing the total distribution costs. Each route must finish at the same depot from which it departed. Similar to the VRP, each customer must be visited once, and the depot and vehicle capacities must be respected. An illustrative representation of MDVRP applied to $\mathrm{HC}$ is presented in Figure 1. 


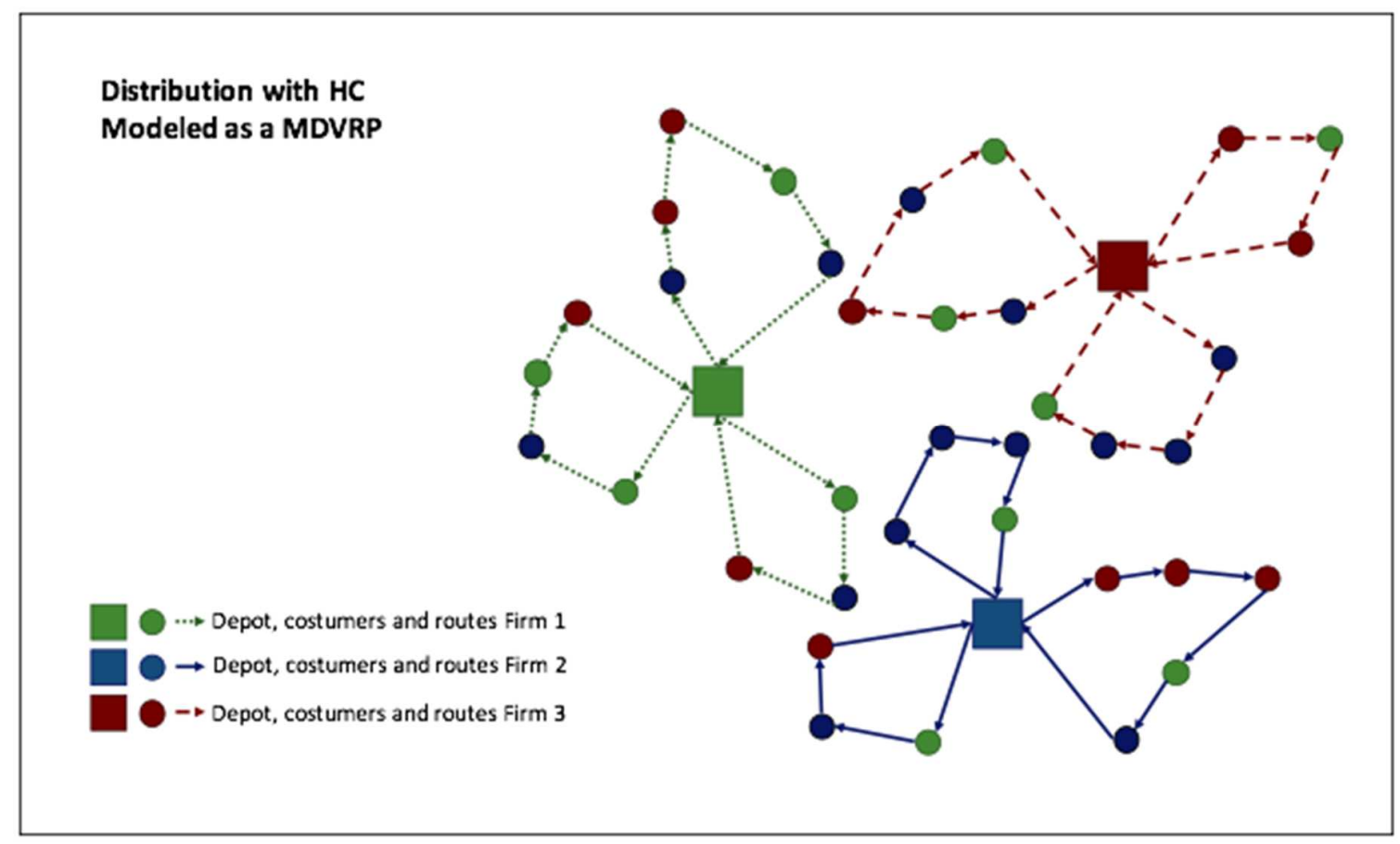

Fig. 1. Representation of MDVRP applied to HC (source: authors' own elaboration)

In terms of complexity, MDVRP is an NP-hard problem due to the fact of being a natural extension of the VRP (Toth and Vigo, 2014). Thus, exact solution methods for NP-hard problems can only provide optimal solutions for small datasets or instances. That is to say that, as the problem size increases (i.e., number of points to be served by the vehicles), exact approaches present computational difficulties to explore efficiently the problem feasible region. Therefore, heuristics and metaheuristics methods need to be used to provide near-optimal solutions to midor large-sized instances or to real-life cases. This work aims to overcome this limitation by proposing a metaheuristic approach based on biased randomization, which is a technique that has been successfully tested in similar routing contexts (Juan et al., 2011; Muñoz-Villamizar, 2013; Quintero-Araujo et al. 2016).

As previously stated, road transportation is responsible for a huge amount of greenhouse gas emissions. Therefore, there is an increasing interest in using more efficient vehicle types from an environmental point of view. The incorporation of 'greener' vehicles has been studied in recent years. However, there are many open issues regarding the use of such kind of vehicles as mentioned by Juan et al. (2016). We have considered that all the aforementioned conditions can be analyzed within the context of a case study in an emerging economy (Colombia), not only in the short but also in the medium term. To do so, we have included all involved costs (both economic and environmental) that can arise in the corresponding planning horizon. In addition, we use competitive solving approaches relying on Operations Research techniques to support our quantitative analysis. It is important to remind that, as this is a case study, these costs are specific to the Colombian case. 


\section{Description of the solution approach}

According to the information given in the previous sections, a metaheuristic approach has been proposed to measure the impact of the usage of electric vehicles in collaborative urban transport networks from a multi-objective perspective. Our purpose searches for the evaluation of the relationship between delivery cost and environmental impact. Thus, we have developed an iterated local search (ILS) algorithm (Lourenço et al., 2010) based on biased randomization (BR) techniques (Juan et al. 2011) in order to solve the MDRVP problem. The choice of such method relies on the fact that recent advances in the field of metaheuristics suggest: $(i)$ the implementation of simple and powerful methodologies in order to facilitate their replicability in real-settings and, (ii) the use of hybrid methods to benefit from the advantages of the underlying techniques.

Hence, we are going to use an ILS to find an initial solution. Then, at each iteration, a perturbation of the obtained local optima will be carried out. Finally, a local search will be also applied to that perturbed solution. The generated solution is accepted as the new current solution under some conditions (Talbi, 2009). BR works considering similar strategies to the Greedy Randomized Adaptive Search Procedure (GRASP) (Resende and Ribeiro, 2003). However, two main differences can be observed among GRASP and BR. Firstly, BR considers all elements potentially eligible at each iteration of the construction process, while GRASP uses a restricted candidate list. Secondly, GRASP applies a uniform probability distribution to choose among the restricted candidate list elements, while BR assigns a higher probability of being chosen to the most promising elements, that is, those that are likely to contribute to a higher improvement of the objective function.

Our method splits up the problem into three sub-problems, to reduce its complexity, but aggregates them in order to guarantee the quality of solutions. The first sub-problem is the customer allocation to depots; the second one is to find the set of routes starting from each depot to serve the corresponding customers; finally, the third one is the allocation of the type of vehicle (i.e. gasoline or electric) to each route, using a multi-objective function.

Our generic global approach, presented in Figure 2, is based on Muñoz-Villamizar et al. (2017) analysi and is composed of three main phases. Phase 1 defines the characteristics of the urban freight transport network. Phase 2 solves customer allocation and routing sub-problems; and, finally, Phase 3 assigns the different vehicle types and creates an efficient relative frontier. Details of each phase are described in Figure 2.

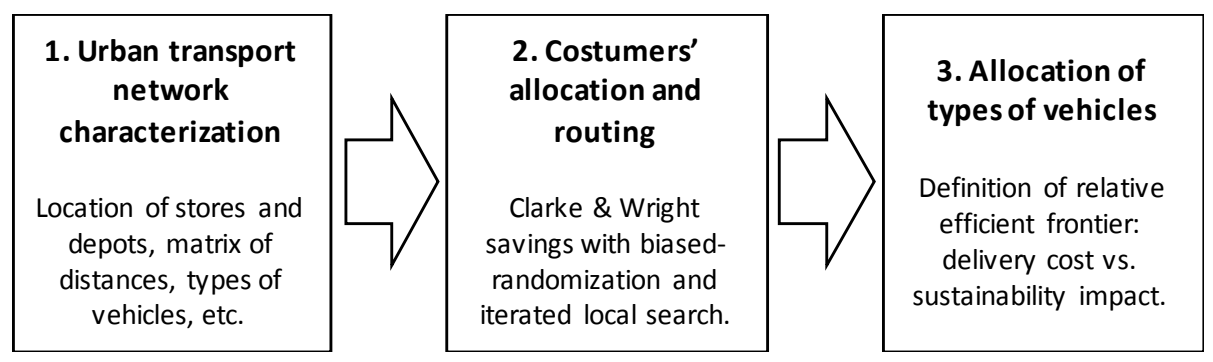


Fig. 2. Global generic approach (source: authors' own elaboration)

\subsection{Characterization of the urban transport network}

In this phase, we identify the elements of the case under study. Key elements are location of depots and delivery points (e.g. stores) selection and corresponding demand, distances/cost between nodes (i.e. travel distances among depots and delivery points and between delivery points themselves). In addition, we consider the main characteristics of the available vehicle types.

As this approach seeks to assess the environmental impact, emission factors for each vehicle type must be calculated in order to compute total $\mathrm{CO}_{2}$ emissions. These emission factors are computed considering $(i)$ the emissions generated by the energy production and, (ii) the emissions due to the transport operation itself. Considering that energy can be generated using different sources (e.g. oil, natural gas, nuclear, hydroelectric or solar), energy production has different costs and emissions depending on both the local diversity of power plants and distribution network efficiency. Therefore, $\mathrm{CO}_{2}$ emissions will be different for each country where this approach is applied. In addition, energy consumption depends on both the given use and the efficiency of the vehicles (i.e. costs and emissions generated in the delivery process directly depend on the activity and usage of fleet vehicles). Estimations of these factors will be shown further in the experiments section.

\subsection{Costumers' allocation and routing}

Having the purpose of determining the customer allocation to depots, we use a distance-based saving list and we apply a biased-randomized selection over this saving list to create allocation maps. Firstly, we compute the marginal savings $S_{i d}$ of assigning a customer $(i)$ to a depot $(d)$ instead of assigning it to the nearest alternative depot $\left(d^{*}\right)$ using the following expression $S_{i d}=C_{i d}$ - $C_{i d} *$. Then, the list of savings is sorted in decreased order. Next, we consider a biasedrandomized selection to the saving list to assign customers to depots. Once all customers have been assigned to depots, we use the biased-randomized version of the Clarke \& Wright savings (CWS) heuristic (Clarke \& Wright 1964) to generate candidate routes. This process is executed during a given time (30 seconds in our case) and the best solution obtained so far is also kept as the basis solution. Due to asymmetric distances, the savings of using the arc $(i, j)$ for route constructions are computed as follow: $S a v_{i j}=C_{i d}+C_{d j}-C_{i j}$. Hence, a perturbation operator is applied over the customer-depot allocations and the new (perturbed) allocations are then routed as previously explained. In order to reduce the risk of being trapped in a local optimum, we use an acceptance criterion alike to the one employed in Simulated Annealing when a non-improving solution is obtained.

Finally, the best customer/depot allocations are selected as the promising ones and a more time intensive routing algorithm is executed (SR-GCWS-CS algorithm proposed by Juan et al. (2011)). This algorithm extends the biased-randomization for the CWS heuristic, by including splitting policies to the VRP's for a divide and conquer strategy and a cache memory. This 
process is executed during 350 iterations. An overview of the procedure is given in Figure 3.

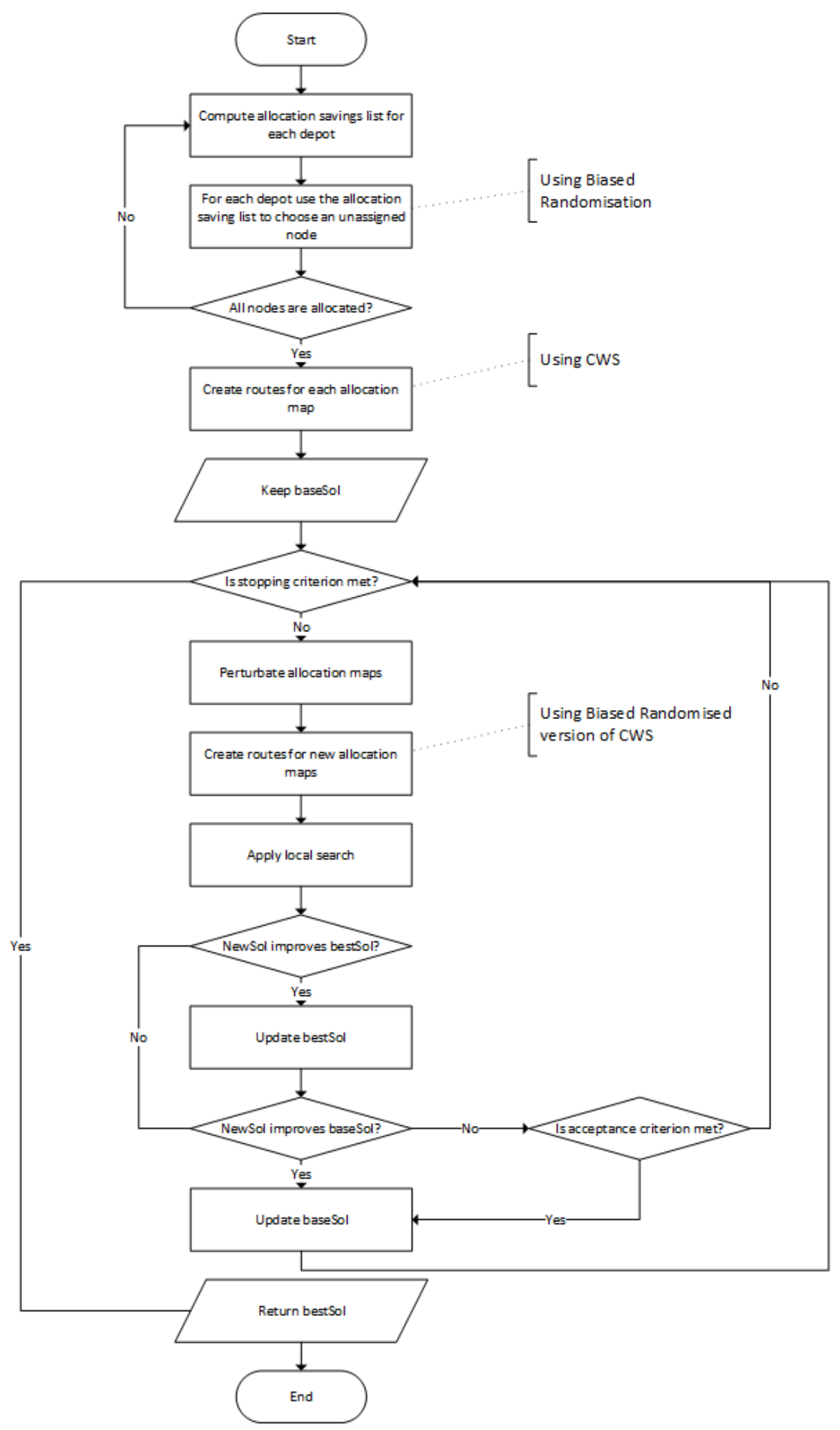

Fig. 3. Flowchart of the algorithm for Phase 2. 


\subsection{Allocation of vehicle types and efficient relative frontier}

After the routes definition by minimizing distance, a multi-objective evaluation is performed to assess the impact of the use of electric vehicles in comparison to gasoline ones, using a relativized efficient frontier. It is important to recall that very few papers have discussed horizontal collaboration or MDVRP through multi-objective / multi-criteria decision-making models. This relativized efficient frontier is proposed by Muñoz-Villamizar et al. (2017). The efficient frontier is the set of non-dominated solutions for the combination of different objectives. Depending on the decision maker preferences, a different solution could be chosen from the efficient frontier. In our approach, two impacts are taken into account in this valuation: economic and environmental costs $\left(\mathrm{CO}_{2}\right.$ emissions). However, other objective functions, as social impact, could be simultaneously evaluated using this methodology of relative analysis. This is, as each impact has different units (i.e. US\$ for the costs and $\mathrm{CO}_{2}$ emissions for the environmental impact), it is convenient to perform the relative analysis of each of them. Thereby, every impact can be evaluated in the same objective function as a weighted-sum of factors. The proposed procedure is different from other known multi-objective approaches and determines the type of required vehicles for each route defined in subsection 4.2. It is important to clarify that this sequential approach implies that the results of the previous phase are going to be the inputs in this one.

The relativized efficient frontier is created using three different objective functions (i.e. $f_{1}, f_{2}$ and $f_{3}$ ). Note that our approach uses one objective function for each evaluated impact (i.e. $f_{1}$ for economic cost and $f_{2}$ for environmental impact) and an additional function that aggregates the two previous ones (i.e. $f_{3}$ ). The first objective function, $f_{1}$, computes the economic cost of using a specific combination of gasoline and electric vehicles in the routes (e.g. route 1 uses an electric car, route 2 a gasoline car, etc.). As mentioned before, in our approach, the economic cost is calculated using the purchase price of each vehicle, its maintenance cost and the cost of used energy in transport operation. Objective function $f_{2}$ computes the environmental impact using the $\mathrm{CO}_{2}$ emissions created by the production of the energy and the emissions created by the consumption of the energy during transportation. According to these ideas, our approach evaluates every possible combination of allocation of vehicle types to each route from Phase 2, with first two functions separately. The best solutions obtained so far, for each objective function, are kept as the basis solution $f_{1}{ }^{*}$ and $f_{2}{ }^{*}$. Then, objective function $f_{3}$ is computed (see Equation 1) with every possible combination of allocation of vehicle used in the previous step. It is important to emphasize that functions $f_{1}$ and $f_{2}$, along with $f_{1}{ }^{*}$ and $f_{2}{ }^{*}$, must be evaluated previously and are inputs of $f_{3}$.

$$
f_{3}=\alpha \frac{f_{1}}{f_{1}^{*}}+(1-\alpha) \frac{f_{2}}{f_{2}^{*}}
$$


Note that the objective function $f_{3}$ is used to calculate a relativized solution. This relative analysis process occurs giving weights to each impact (i.e. $\alpha=$ weight for economic cost and $1-\alpha=$ weight for $\mathrm{CO}_{2}$ emissions). According to the preferences of the decision maker, different weights for each impact can be evaluated. It should be noted that the minimum value for this third function is 1 , as a result of the relative analysis process. Thus, for each selected weight of each impact (i.e. $\alpha$ and $1-\alpha$ ), the best solution of $f_{3}$ obtained so far, is kept as the basis solution. Finally, the efficient frontier is created using the best results in third function, $f_{3}$, for all combinations of selected weights.

\section{Experiments and analysis of results}

In order to perform some numerical tests, and as a quantitative sample, the proposed framework was tested using real data from a case study in Colombia. The case study method was selected in order to explore and investigate this contemporary phenomenon in the real-life context of urban distribution in a populous city (Bogotá) in emerging economy (Colombia). The aim is to explain the phenomenon through detailed contextual analysis of a limited number of conditions and their relationships. Hence, the three major and most representative networks of convenience stores (proximity shops) operating in Bogotá, Colombia, were selected in order to closely examine the data within this specific context. The rationale behind this choice is based on the fundamentals of case study as a research method (Yin 2017) where a small geographical area or a very limited number of individuals as the subjects of study is selected. Yin (2017) defines the case study research method "as an empirical inquiry that investigates a contemporary phenomenon within its real-life context; when the boundaries between phenomenon and context are not clearly evident; and in which multiple sources of evidence are used".

Similarly, theoretical experiments with different costs and demand projections have been performed to analyze short- and medium-term impacts generated by the use of electric vehicles in the configuration of the transportation fleet. As an extension of our previous work (see MuñozVillamizar et al. 2017), we have designed a more efficient procedure (i.e. a metaheuristic algorithm) to evaluate the use of electric vehicles in collaborative urban transport networks from a multi-objective perspective. Thus, Muñoz-Villamizar et al. (2017) presented a heuristic approach based in MILP models, which is going to be compared with the results obtained in this study, as a first step, to check the improvement in the solution procedure. Then, a further analysis will be performed taking into account the maintenance costs of vehicles and considering longer time horizons for the operation (i.e. 1 and 5 years). Note that, the model presented by MuñozVillamizar et al. (2017) is a MILP-based approach, which is not able to handle mid- to largesized instances. Therefore, the comparison of these two approaches for 1 and 5-year scenarios is not possible. In addition, three scenarios with different energy costs (i.e. electricity and gasoline) were evaluated in order to run a cost sensitivity analysis.

The rest of this section is structured as follows. The characterization of the urban transport network in the case under study is presented in subsection 5.2. Subsection 5.3 shows a comparison against the results of Muñoz-Villamizar et al. (2017). Subsections 5.4 and 5.5. 
present short and medium-term assessment of the use of electric vehicles for one and five years, respectively. Finally, Subsection 5.6 presents a cost sensitivity analysis for the fifth year of operation.

\subsection{Characterization of a case study: Urban distribution in Bogotá, Colombia}

The proposed approach was tested using real data from the three major networks of convenience stores (proximity shops) operating in Bogotá, Colombia. Bogotá is the capital of Colombia and its largest city. Its population is around 10 million inhabitants. It is the fifth largest city in Latin America and twenty-fifth in the world (City Mayors, 2015). The selection of Bogotá as the city under study allows us to have a complex and complete example of the behavior of cities in emerging economies.

Current locations of proximity shops of selected companies are obtained using a geographical information system (GIS). For privacy reasons, we are going to name the three aforementioned proximity shops as Company E, Company $\mathrm{O}$ and Company M, respectively. Company E owns 16 stores, Company $\mathrm{O}$ owns 35 stores, and Company $\mathrm{M}$ owns 10 stores, for a total of 61 stores (delivery points). The asymmetric origin-destination matrix was obtained using actual driving distances using Google Maps ${ }^{\mathrm{TM}}$ mapping service (accessed: 24 August 2016). Among the different options provided by the software, the shortest path was kept for calculations in this study.

For the short-term evaluation (i.e. 1 year), weekly demands for all the 61 delivery points were randomly generated from a uniform distribution between the $1 \%$ and the $10 \%$ of the maximum vehicle load capacity $D_{i} \sim U(0.01 * C A P ; 0.10 * C A P)$. For the mid-term evaluation (i.e. 5 years), annual demand increases of $5 \%$ and $25 \%$ are added to this random generation. In order to replicate the experiments, full origin-destination matrices and stochastic demand sets are available upon request to the corresponding author of this paper. It is also assumed that availability of the necessary vehicles achieves a $100 \%$ of service level.

Selected vehicles for urban freight transport were Renault Kangoo Van (gasoline vehicle) and Renault Kangoo Z.E. (electric vehicle). Characteristics of these used vehicles are resumed in Table 2. Note that both models have the same payload and are from a similar category, thus they can be compared one each other. As mentioned before, the economic cost components that we consider in this study are the cost of used energy (i.e., electricity or gasoline), the price of each vehicle and the yearly maintenance cost (Table 3 ).

Table 2. Characteristics of used vehicles (Renault Colombia, 2016)

\begin{tabular}{lcc}
\hline & $\begin{array}{c}\text { Kangoo Van } \\
\text { (Gasoline Car) }\end{array}$ & $\begin{array}{c}\text { Kangoo Z.E. } \\
\text { (Green Car) }\end{array}$ \\
\hline Price & USD\$ 15,423.73 & USD\$ 28,813.56 \\
Payload & $650 \mathrm{~kg}$ & $650 \mathrm{~kg}$
\end{tabular}




\begin{tabular}{lcc} 
Energy Consumption & 4.3 liters $/ 100 \mathrm{~km}$ & $16.2 \mathrm{kWh} / 100 \mathrm{~km} *$ \\
CO2 emissions & $112 \mathrm{~g} / \mathrm{km}$ & $0 \mathrm{~g} / \mathrm{km}$ \\
\hline
\end{tabular}

*kWh consumption by Next Greencar ${ }^{\mathrm{TM}},(2016)$

Table 3. Approximate yearly maintenance cost (US\$) per type of vehicle (Audatex, 2016)

\begin{tabular}{ccc}
\hline & $\begin{array}{c}\text { Kangoo Van } \\
\text { (Gasoline Car) }\end{array}$ & $\begin{array}{c}\text { Kangoo Z.E. } \\
\text { (Green Car) }\end{array}$ \\
\hline Year 1 & US\$ 324 & US\$ 138 \\
Year 2 & US\$ 430 & US\$ 457 \\
Year 3 & US\$ 351 & US\$ 269 \\
Year 4 & US\$733 & US\$ 524 \\
Year 5 & US\$ 667 & US\$ 138 \\
\hline
\end{tabular}

Alternatively, environmental components of the distribution process are the $\mathrm{CO}_{2}$ emissions generated by the production of the energy (i.e. electricity or gasoline) and the emissions by the consumption of the energy itself. As also mentioned earlier in this paper, each country has a mix of power plants that use different energy sources; so, the economic cost and the $\mathrm{CO}_{2}$ emissions will be different for obtaining electricity or gasoline in each country.

According to the Colombian Ministry of Mines and Energy, 64\% of electricity in the country is produced by water resources, $31 \%$ by thermal resources and other sectors such as wind energy are now being explored (CREG, 2015). The price of electricity in Bogotá is $\$ 0.18 / \mathrm{kWh}$ (CODENSA, 2016) and the price of gasoline is $\$ 0.67$ per liter (GlobalPetrolPrices.com, 2016). Colombia has a rate of $0.199 \mathrm{~kg}$ of $\mathrm{CO}_{2}$ emissions per $\mathrm{kWh}$ of electric energy produced and 2.33 $\mathrm{kg}$ of $\mathrm{CO}_{2}$ emissions per liter of gasoline produced (UPME, 2016). These factors are used to calculate the quantity of emissions created by the use of each source of energy. Finally, with this data, cost and $\mathrm{CO}_{2}$ emissions per kilometer were calculated for both type of vehicles and are presented in Table 4. Note that $\mathrm{CO}_{2}$ emissions per kilometer are computed adding the emissions by using the vehicle and the emissions generated by producing their respective energy source (i.e. gas or electricity).

Table 4. Cost and emissions per type of vehicle

\begin{tabular}{lcc}
\hline & $\begin{array}{c}\text { Kangoo Van } \\
\text { (Gasoline Car) }\end{array}$ & $\begin{array}{c}\text { Kangoo Z.E. } \\
\text { (Green Car) }\end{array}$ \\
\hline Cost / km & 0.029 US\$ $/ \mathrm{km}$ & 0.023 US\$/ km \\
CO2 emissions / km & $0.212 \mathrm{~kg} / \mathrm{km}$ & $0.032 \mathrm{~kg} / \mathrm{km}$ \\
\hline
\end{tabular}

\subsection{Comparing our procedure}

According to the information given in previous paragraphs, Muñoz-Villamizar et al. (2017) 
presented a heuristic approach based on MILP models to evaluate the usage of electric vehicles in collaborative urban transport networks from a multi-objective perspective. In order to carry out statistical analyses, ten different sets of demands (instances) for all the 61 delivery points were generated. Demands were randomly generated, as explained in the previous subsection, from a uniform distribution between the $1 \%$ and the $10 \%$ of the maximum vehicle load capacity $D_{i} \sim$ $U(0.01 * C A P ; 0.10 * C A P)$. Additionally, results from Muñoz-Villamizar et al. (2017) were updated with the latest data of vehicles (Renault Colombia, 2016), gasoline (Globalprice.com, 2016) and electricity (CODENSA, 2016) costs and $\mathrm{CO}_{2}$ emissions (UPME, 2016).

As an initial comparison, the Muñoz-Villamizar et al.'s (2017) results for routing and our results are presented in Figure 4. Notice that our approach was able to improve the routing solutions provided by the Muñoz-Villamizar et al.'s (2017) heuristic method in a $10.3 \%$ on average. This value is equivalent to an average reduction of $23 \mathrm{~km}$ per instance in routing distances. Nevertheless, given the cost of traveling one kilometer (less than 0,029 US\$/kilometer), money savings are not as significant as the distance reduction.

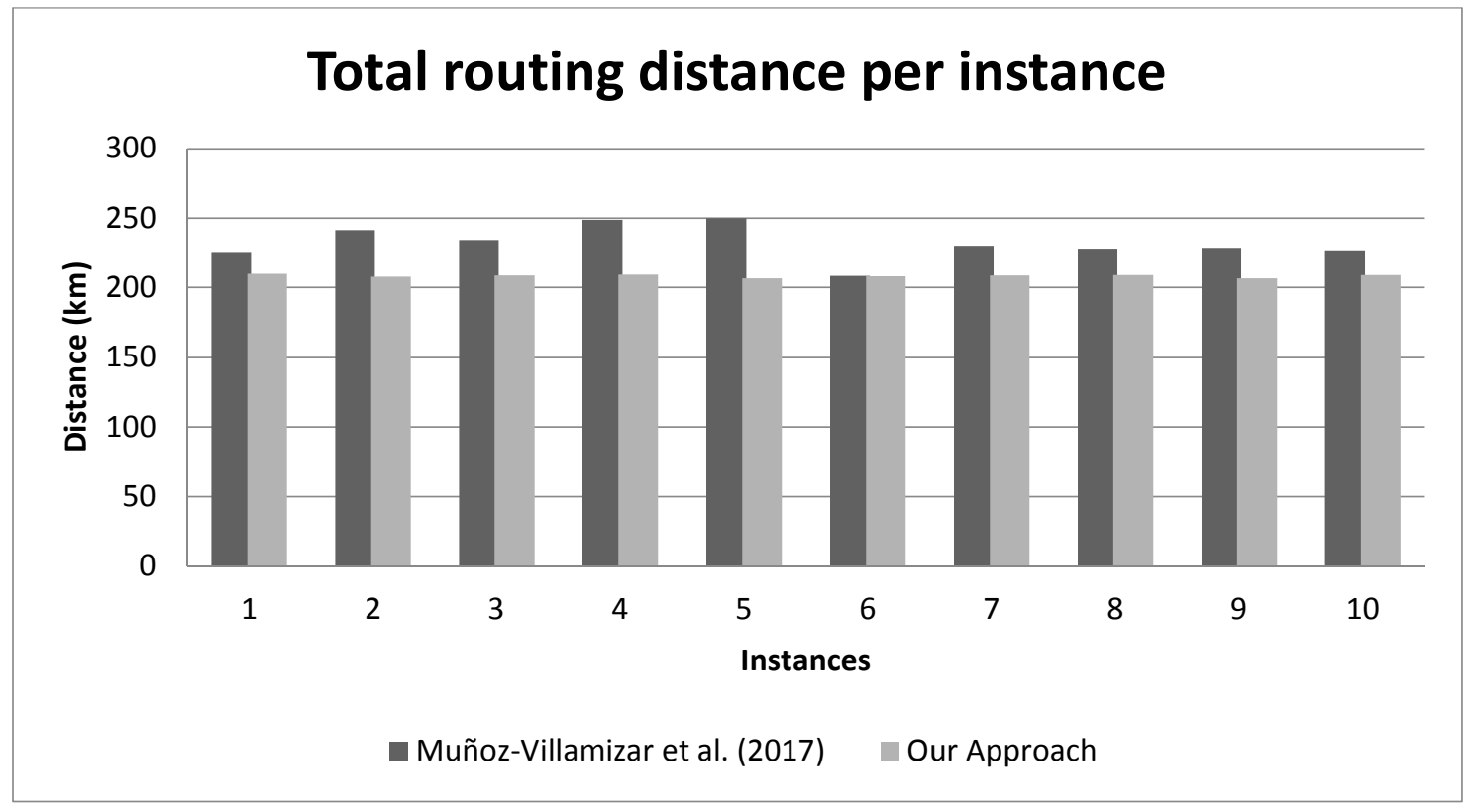

Fig. 4. Routing distance comparison: Muñoz-Villamizar et. Al (2017) vs Our Approach

Finally, complete results of Muñoz-Villamizar et al. (2017) (with updated data) and our approach are presented in Table 5 and Table 6, respectively; while efficiency frontiers for both approaches are shown in Figure 5. Different values of $\alpha$ (i.e. $\alpha=$ weight for cost and $1-\alpha=$ weight for $\mathrm{CO}_{2}$ emissions) were proposed to show the behavior of the efficiency frontier. That is, only the $\alpha$ values that changed the allocation of vehicle types for each approach are presented. Improved results in cost $\left(f_{1}\right)$ and emissions $\left(f_{2}\right)$ functions, and hence in the efficiency frontier, are due to the improvement of the solution method. This is, the proposed approach makes a better customer allocation and an improved vehicle routing. Small improvements in cost functions are due to the low costs of traveling to kilometer compared with the purchasing cost of each vehicle. Therefore, 
we can state a preliminary good performance of the proposed method.

Table 5. Muñoz-Villamizar et al. (2017) results: Economic cost (\$), $\mathrm{CO}_{2}$ emissions (kg), relative function value and percentage of used vehicles that are electric.

\begin{tabular}{ccccc}
\hline$\alpha$ & $\begin{array}{c}\text { Cost function } \\
Z_{1}\end{array}$ & $\begin{array}{c}\text { Environmental function } \\
Z_{2}\end{array}$ & $\begin{array}{c}\text { Relative function } \\
Z_{3}\end{array}$ & $\begin{array}{c}\text { \% of electric } \\
\text { vehicles }\end{array}$ \\
\hline 1.00 & 61,702 & 49.2 & 1.00 & $0 \%$ \\
0.98 & 63,041 & 47.6 & 1.56 & $3 \%$ \\
0.78 & 71,074 & 40.1 & 1.66 & $18 \%$ \\
0.58 & 83,125 & 30.0 & 1.70 & $40 \%$ \\
0.33 & 96,514 & 19.5 & 1.71 & $65 \%$ \\
0.13 & 105,887 & 12.8 & 1.72 & $83 \%$ \\
0.03 & 112,582 & 8.7 & 1.69 & $95 \%$ \\
0.00 & 115,260 & 7.4 & 1.00 & $100 \%$ \\
\hline
\end{tabular}

Table 6. Our approach results: Economic cost $(\$), \mathrm{CO}_{2}$ emissions $(\mathrm{kg})$, relative function value and percentage of used vehicles that are electric.

\begin{tabular}{ccccc}
\hline$\alpha$ & $\begin{array}{c}\text { Cost function } \\
Z_{1}\end{array}$ & $\begin{array}{c}\text { Environmental function } \\
Z_{2}\end{array}$ & $\begin{array}{c}\text { Relative function } \\
Z_{3}\end{array}$ & $\begin{array}{c}\text { \% of electric } \\
\text { vehicles }\end{array}$ \\
\hline 1.00 & 61,701 & 44.2 & 1.0 & $0 \%$ \\
0.89 & 63,040 & 43.0 & 1.6 & $3 \%$ \\
0.88 & 73,751 & 34.2 & 1.7 & $23 \%$ \\
0.87 & 84,463 & 26.2 & 1.7 & $43 \%$ \\
0.86 & 97,853 & 17.0 & 1.7 & $68 \%$ \\
0.85 & 108,564 & 10.3 & 1.7 & $88 \%$ \\
0.82 & 113,920 & 7.3 & 1.7 & $98 \%$ \\
0.00 & 115,259 & 6.7 & 1.0 & $100 \%$ \\
\hline
\end{tabular}




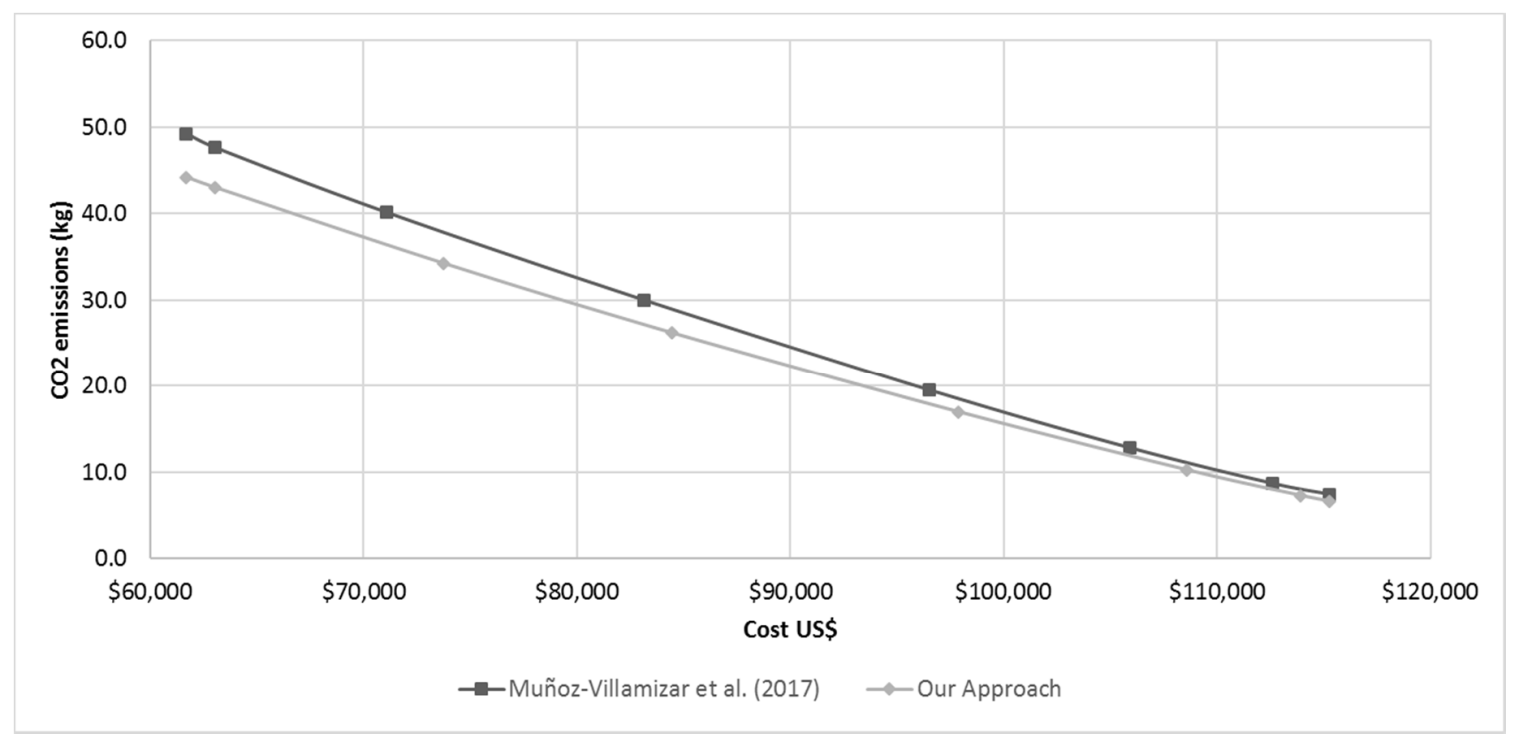

Fig. 5. Efficient frontier comparison: Muñoz-Villamizar et al (2017) vs Our Approach

\subsection{Short-term evaluation}

Weekly demands for all the 61 delivery points were randomly generated from a uniform distribution in order to analyze short impacts in the use of electric vehicles in the configuration of the transport network, (see subsection 5.2). Therefore, 52 different instances were evaluated with the proposed approach to simulate the complete transport operation for a full year. This experiment allows a better comparison between the costs of acquiring the vehicles and the costs of the transport process. Results for this scenario are presented in Table 7 and Figure 6 . Note that this data corresponds to total cost (emissions) for one-year operation. As mentioned before, different values of $\alpha$ were proposed to fully show the behavior of the efficiency frontier. For this one-year evaluation, the cheapest option is to keep the entire gasoline fleet. However, after considering a 0.04 value in the weight for $\mathrm{CO}_{2}$ emissions (i.e. $1-\alpha$ ) the optimal solution is made by a complete electric fleet. This is, for the $\alpha$ range $[0.965 ; 1]$ there is, at least, one gasoline vehicle. As soon as the $\alpha$ value is less than 0.965 all vehicles become electric. Thus, the improvement in the environmental impact is, relatively, much greater than the cost of having a fleet of electric vehicles. In this case, having the entire electric fleet of vehicles generates an economic overrun of $22 \%$, with an $88 \%$ reduction in the environmental impact; in comparison with the scenario of having the entire fleet of gasoline vehicles. 
Table 7. Our approach results for one-year operation: Economic cost (\$), $\mathrm{CO}_{2}$ emissions (kg), relative function value and percentage of used vehicles that are electric.

\begin{tabular}{ccccc}
\hline$\alpha$ & $\begin{array}{c}\text { Cost function } \\
Z_{1}\end{array}$ & $\begin{array}{c}\text { Environmental function } \\
Z_{2}\end{array}$ & $\begin{array}{c}\text { Relative function } \\
Z_{3}\end{array}$ & $\begin{array}{c}\text { \% of electric } \\
\text { vehicles }\end{array}$ \\
\hline 1.00 & 129,579 & 190,927 & 1.0 & $0 \%$ \\
0.975 & 135,407 & 140,895 & 1.2 & $25 \%$ \\
0.97 & 142,005 & 97,362 & 1.2 & $50 \%$ \\
0.965 & 149,000 & 57,168 & 1.2 & $75 \%$ \\
0.00 & 156,727 & 23,149 & 1.0 & $100 \%$ \\
\hline
\end{tabular}

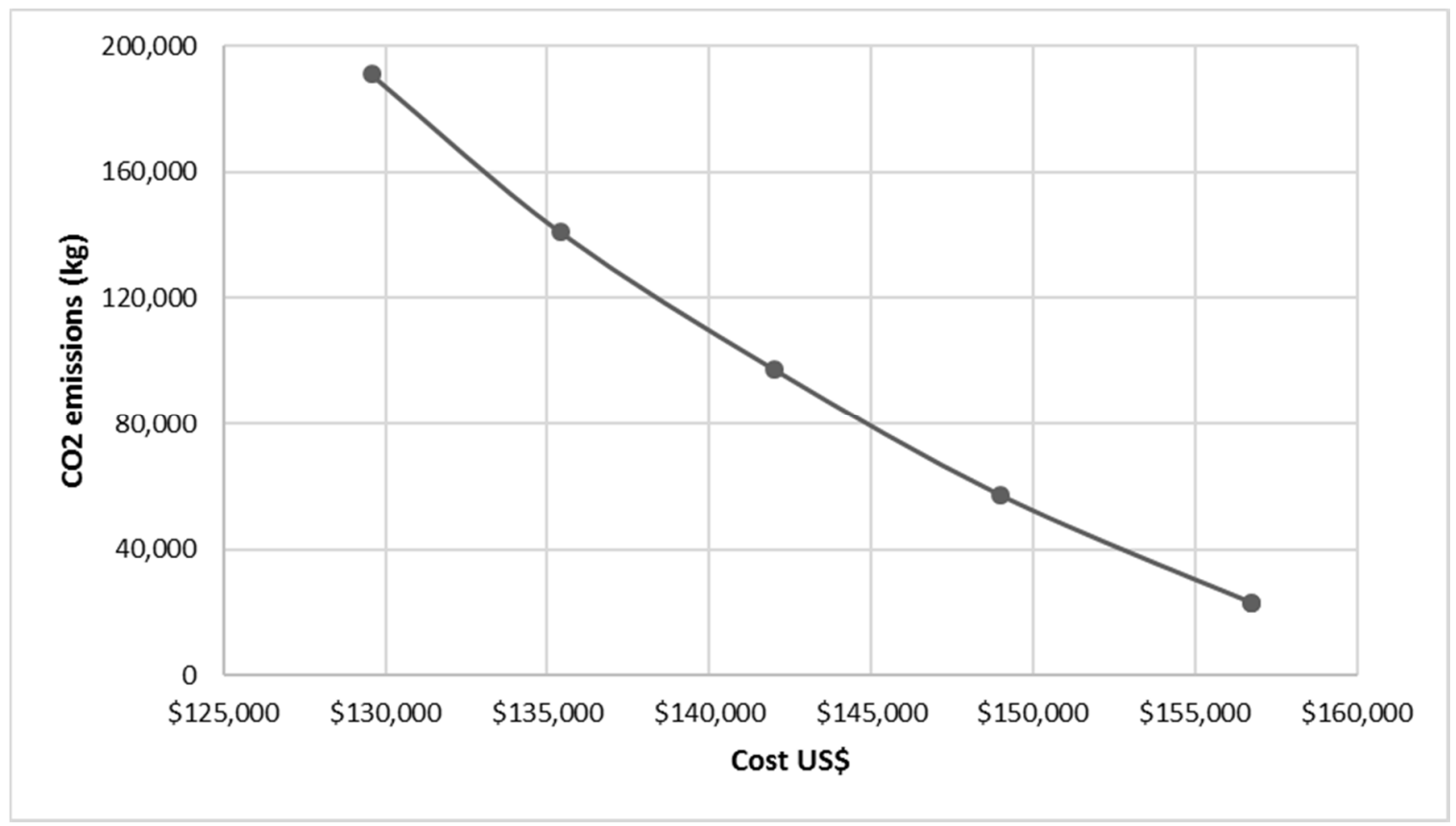

Fig. 6. Efficient frontier for one-year operation.

\subsection{Mid-term evaluation}

For a better understanding of the transport management, a scenario of five years' operation has been evaluated. For this mid-term evaluation on the using of electric vehicles in urban freight transport collaborative networks, two additional key aspects have been taken into account: the incorporation of the yearly maintenance cost (see Table 3) and the variations in customer demands to this random generation (see subsection 5.2). For the case of the variations in customer demands, two different annual increases of 5\% and $25 \%$ have been separately evaluated in order to analyze their impact in low and high demand growth. Therefore, 260 instances were generated for each annual increase for a total of 520 weekly demands for all the 61 delivery 
points. Similarly to other situations, the full origin-destination matrices and demand sets are available upon request to the corresponding author of this paper.

\subsubsection{Annual increase in demand by $5 \%$}

Results of applying the proposed approach for a time horizon of 5 years with annuals increases of $5 \%$ in demands are presented in Table 8 and Figure 7. An unexpected result with two extremes is obtained. For this scenario, the cheapest option is to keep just one gasoline vehicle. Once again, after a 0.04 value in the weight for $\mathrm{CO}_{2}$ emissions (i.e. 1- $\alpha$ ) the optimal solution is the selection of a complete electric fleet. That is, for the $\alpha$ range $[0.96 ; 1]$ there is at least one gasoline vehicle. As soon as the $\alpha$ value is less than 0.96 all vehicles become electric. The main reason for this result is that the maintenance costs of gasoline vehicles are, in med-term, higher than the maintenance costs of electric vehicles. In this scenario, having the entire electric fleet of vehicles generates an economic overrun of only $2 \%$, but a reduction of almost $29 \%$ in the environmental impact; over having a $20 \%$ of gasoline vehicles (i.e. one gasoline vehicle in the fleet).

Table 8. Our approach results for five years with annual increments of $5 \%$ in demand

\begin{tabular}{ccccc}
\hline$\alpha$ & $\begin{array}{c}\text { Cost function } \\
Z_{1}\end{array}$ & $\begin{array}{c}\text { Environmental function } \\
Z_{2}\end{array}$ & $\begin{array}{c}\text { Relative function } \\
Z_{3}\end{array}$ & $\begin{array}{c}\% \text { of electric } \\
\text { vehicles }\end{array}$ \\
\hline 1.00 & 294,577 & 167,011 & 1.00 & $80 \%$ \\
0.96 & 294,577 & 167,011 & 1.02 & $80 \%$ \\
0.00 & 300,388 & 118,872 & 1.00 & $100 \%$ \\
\hline
\end{tabular}

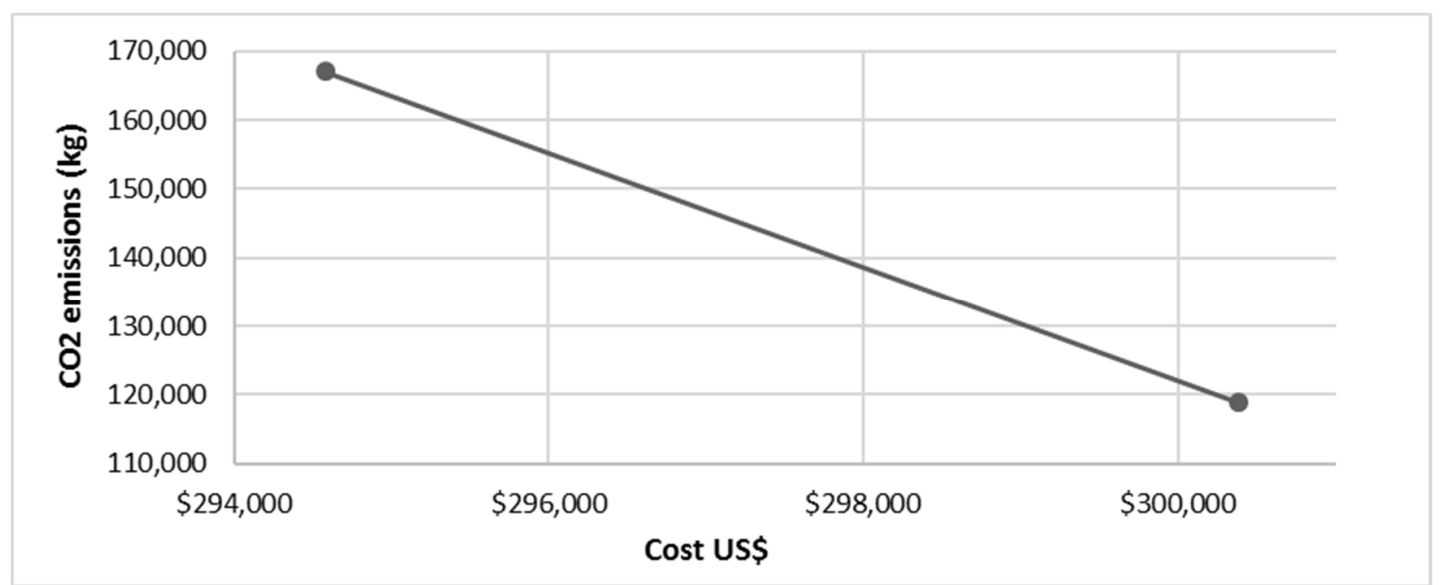

Fig. 7. Efficient frontier for five-year operation with annual increments of $5 \%$ in demand

Additionally, and for a better understanding of these results, Figure 8 shows the number of vehicles used annually as demand grows when the weight for cost is equal to 1.00 (i.e. $\alpha=1$ ). Note that there is only one gasoline vehicle and that it is purchased in the third year. Thus, it is not necessary to analyze other values of $\alpha$ as there is no other different combination for the allocation of the different vehicle types. This scenario asserts that electric vehicles are more profitable in 
mid-term, while gasoline vehicles are more profitable in the short-term because of their lower purchase price. It is important to emphasize that demand increase is very low. Thus, it is only necessary to purchase an additional vehicle to completely meet the demand during the last 3 years of operation. Since this last vehicle will be used only for 3 years, it is more profitable to buy a gasoline vehicle than an electric one.

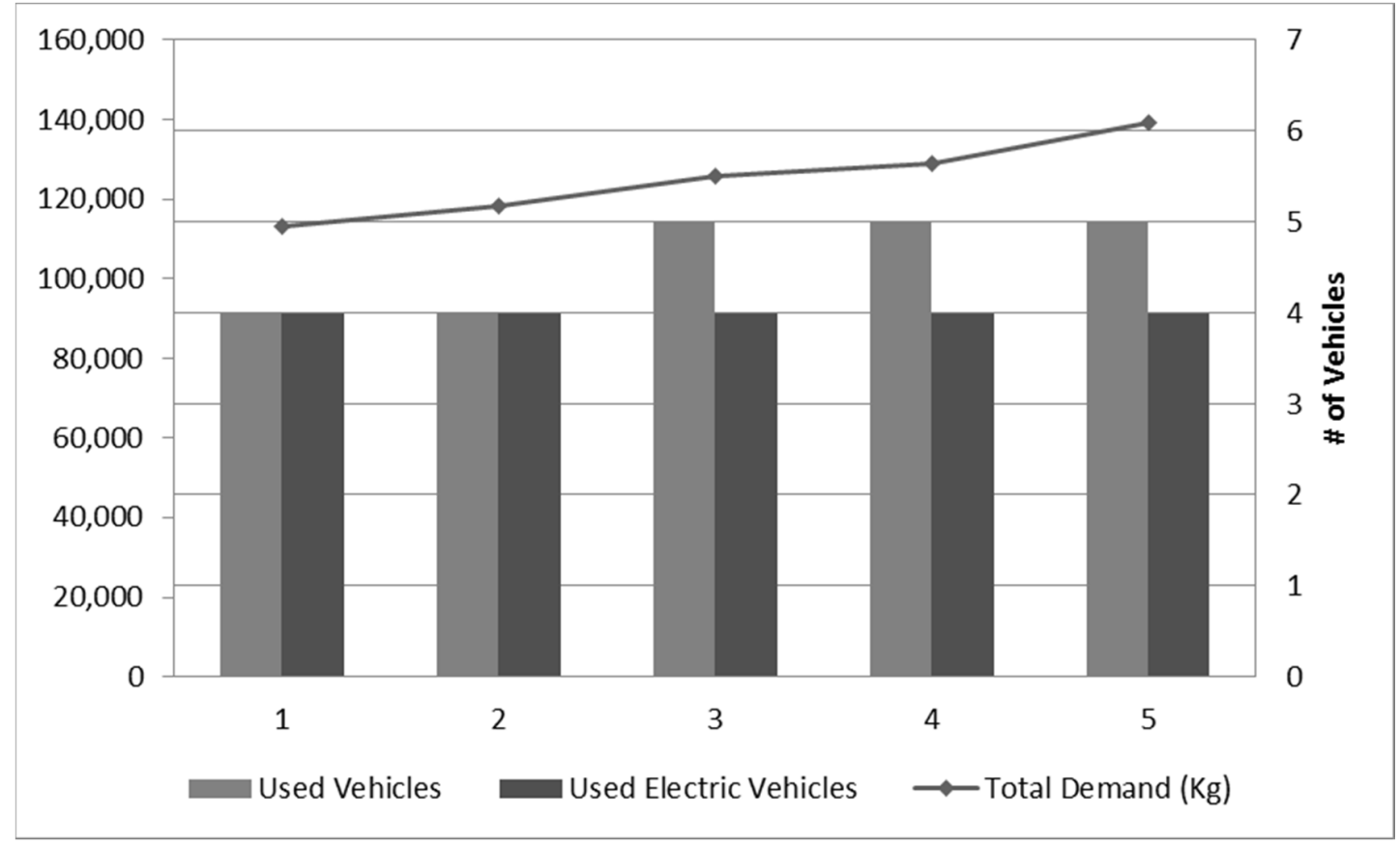

Fig. 8. Yearly demand and used vehicles with $\alpha=1$.

\subsubsection{Annual increase in demand by $25 \%$}

The last scenario evaluates a $25 \%$ annual increase in demand for 5 years. Results of applying the proposed approach are presented in Table 9 and Figure 9. In this scenario, the cheapest option is to keep a $50 \%$ of gasoline fleet and the other $50 \%$ of the electric fleet. Nevertheless, only after a 0.56 value in the weight for $\mathrm{CO}_{2}$ emissions (i.e. 1- $\alpha$ ), the optimal solution would include a complete electric fleet. In this scenario, having a complete electric fleet generates an economic overrun of only $8 \%$, with a reduction of almost $56 \%$ in the environmental impact; in comparison with having a $50 \%$ of gasoline fleet.

Table 9. Our approach results for five years with annual increments of $5 \%$ in demand

\begin{tabular}{ccccc}
\hline$\alpha$ & $\begin{array}{c}\text { Cost function } \\
Z_{1}\end{array}$ & $\begin{array}{c}\text { Environmental function } \\
Z_{2}\end{array}$ & $\begin{array}{c}\text { Relative function } \\
Z_{3}\end{array}$ & $\begin{array}{c}\text { \% of electric } \\
\text { vehicles }\end{array}$ \\
\hline 1.00 & 454,564 & 318,045 & 1.00 & $50 \%$ \\
0.97 & 456,721 & 239,100 & 1.03 & $60 \%$
\end{tabular}




\begin{tabular}{lllll}
0.92 & 462,131 & 187,585 & 1.04 & $70 \%$ \\
0.86 & 470,512 & 160,416 & 1.05 & $80 \%$ \\
0.44 & 480,026 & 143,020 & 1.04 & $90 \%$ \\
0.00 & 492,327 & 140,295 & 1.00 & $100 \%$ \\
\hline
\end{tabular}

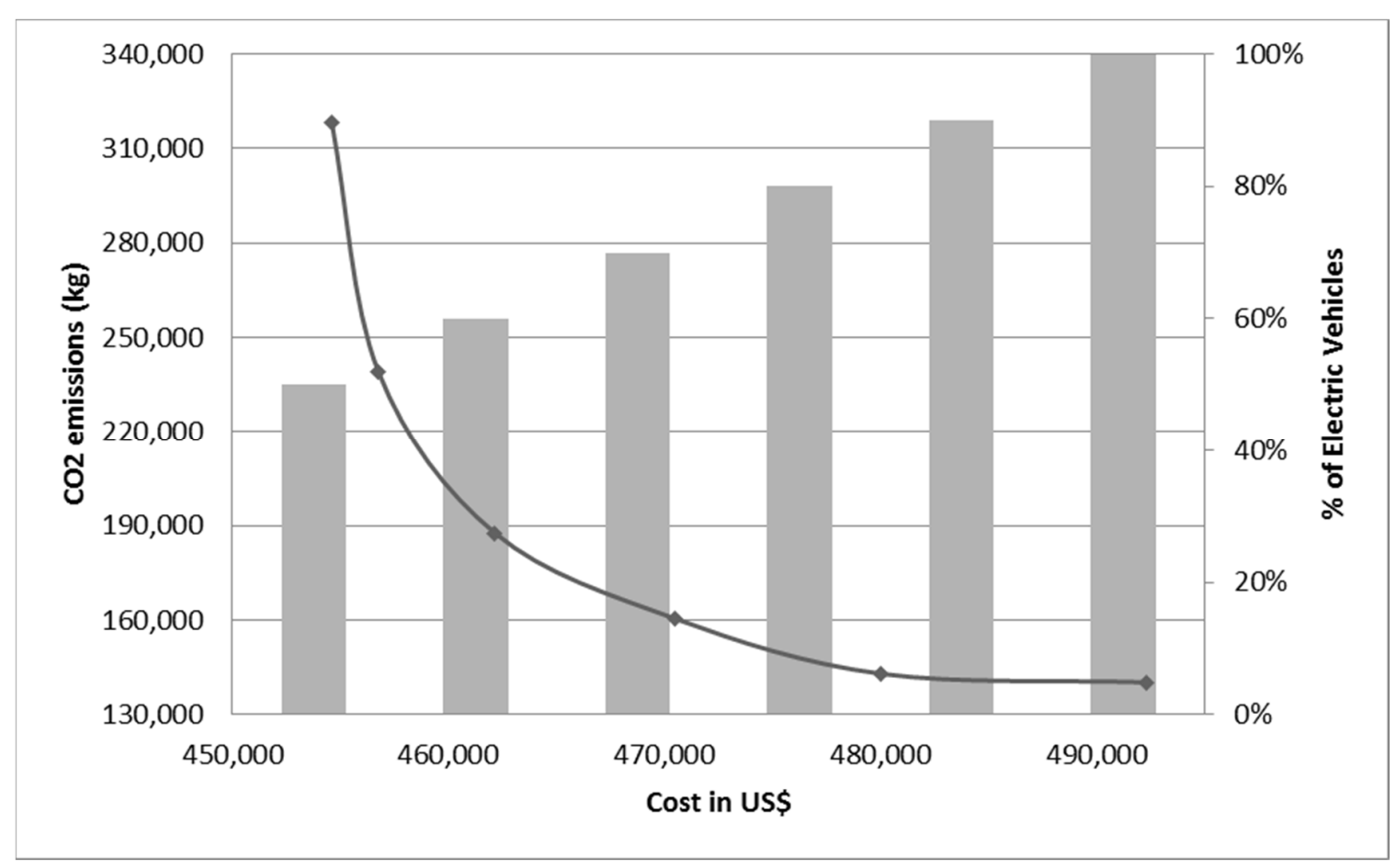

Fig. 9. Efficient frontier for five-year operation with annual increments of $25 \%$ in demand

This solution initially appears different from the results obtained in the previous scenarios. However, the results have the same explanation. Figure 10 shows the number of vehicles used yearly as demand grows when only the economic impact is taken into account (i.e. $\alpha=1$ ). In this case, a fixed number of electric vehicles is purchased from the first year (i.e. 4 vehicles) and, as demand increases, only in the second year a new electric vehicle is purchased. Then, only gasoline vehicles are purchased to meet customer requirements. Once again, it is confirmed that electric vehicles are more profitable in a 4-5 years period of evaluation, while gasoline vehicles are more profitable in a 1-3 years' time-horizon. 


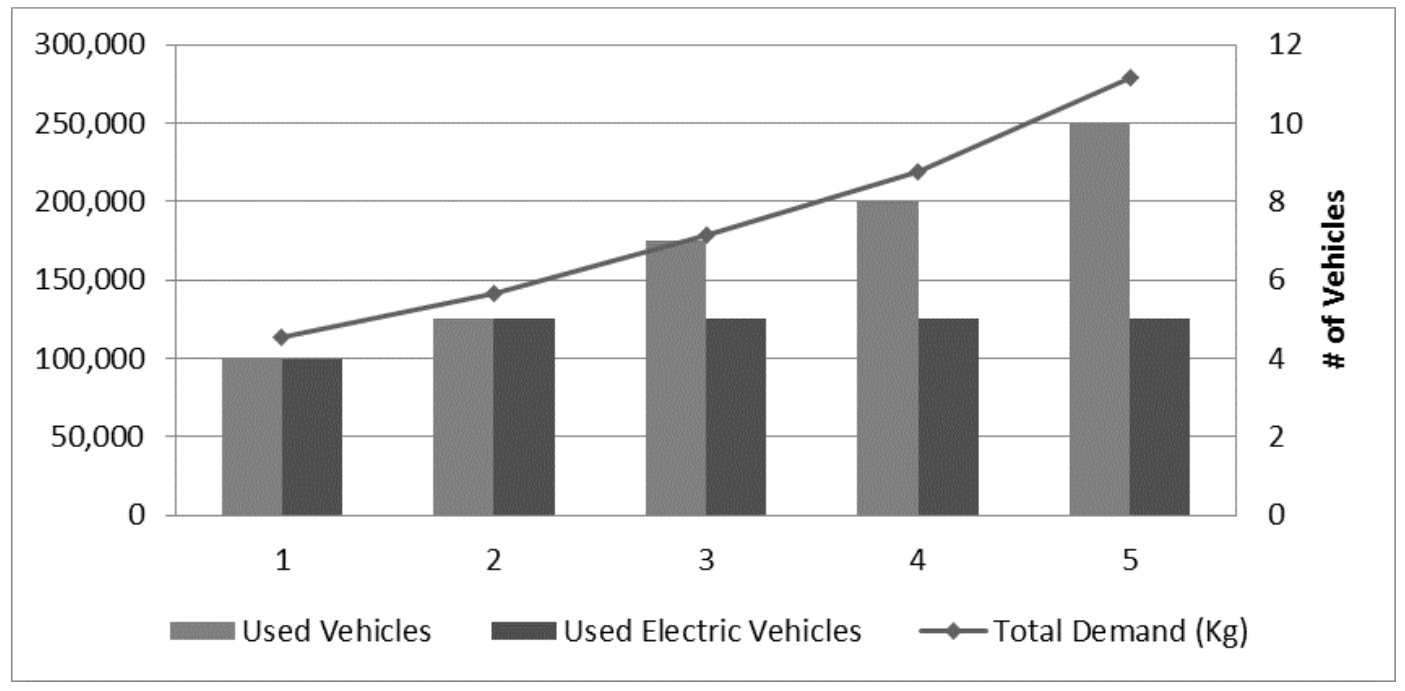

Fig. 10. Yearly demand and used vehicles with $\alpha=1$.

Another remarkable aspect of this scenario is that a considerable amount electric vehicles (EVs) are profitable for any value of $\alpha$ or 1- $\alpha$ (i.e. weight for economic cost and weight for environmental impact. respectively). As it can be seen in Figure 11, at least $50 \%$ of the fleet of vehicles must be electric for any combination of the multi-objective function. This confirms once again that electric vehicles are economically and environmentally profitable for mid-term evaluation.

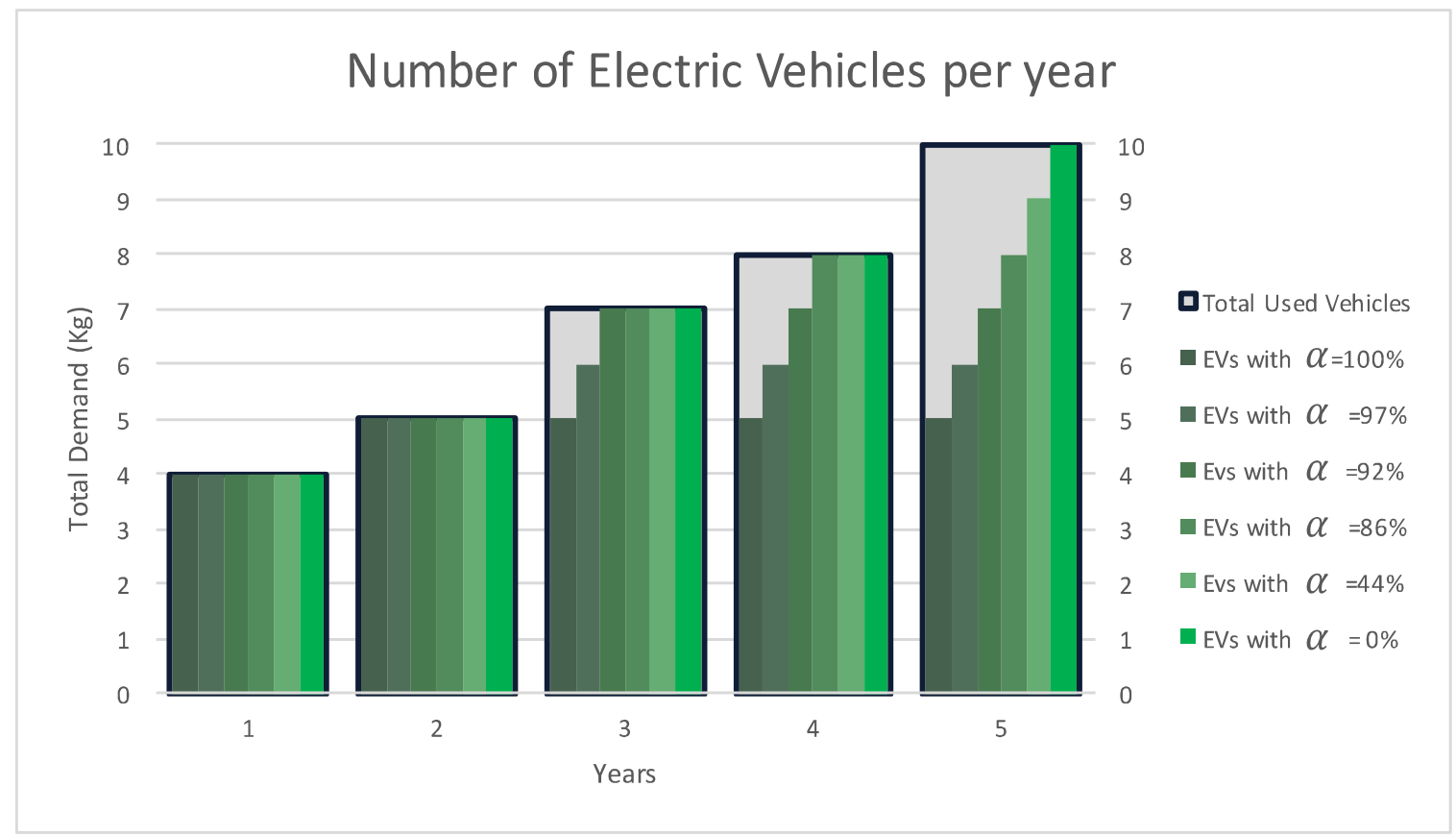

Fig. 11. Number of used electric vehicles each year according to $\alpha$ values. 


\subsection{Cost sensitivity analysis}

Due to the fact that this study is related to a Colombian case, we have to take into account the effect of the costs variability of both energy sources, i.e., gasoline and electricity. On the one hand, gasoline costs in Colombia are revised and updated every month due to the variation of the international oil price. On the other hand, as the $61 \%$ of the electricity generated in the country is by water resources, its price is highly influenced by the presence of rainy and dry seasons. In the first case, energy costs tend to decrease while in the second case, electricity costs have an increase tendency. The selected values for these variations are based on their observed historical behavior. Thus, a sensitivity analysis is required in order to refine our findings. To do so, different energy costs have been evaluated. That is, three additional scenarios with different increases in electricity and/or gasoline costs were generated for the fifth year of scenario in subsection 5.5.2. The analysis of scenarios with different costs can be used to see the impact of the proposed approach in other companies/contexts:

- Scenario 0 is the current situation of the fifth year of operation with an annual increase in demand of $25 \%$. In this scenario, there is no variation in energy costs.

- For Scenario A, a 3\% increase in the cost of gasoline is assessed.

- For Scenario B, a $10 \%$ increase in the cost of electricity is evaluated.

- For Scenario C, a simultaneous increase of 3\% in gasoline cost and $10 \%$ in the cost of electricity are evaluated.

Efficient frontiers for the three scenarios are presented in Figure 12. It is important to note that, as only the fifth year is evaluated, maintenance costs are not taken into account. Consequently, results are similar to the short-term evaluation of subsection 5.4. That is, the cheapest option is to keep the entire gasoline fleet. Analogously in every scenario, as soon as the $\alpha$ value is less than 0.90, all vehicles become electric (see Table 10). These results were expected since the increase in energy costs are relatively much smaller than the environmental benefits of having an electric fleet. 


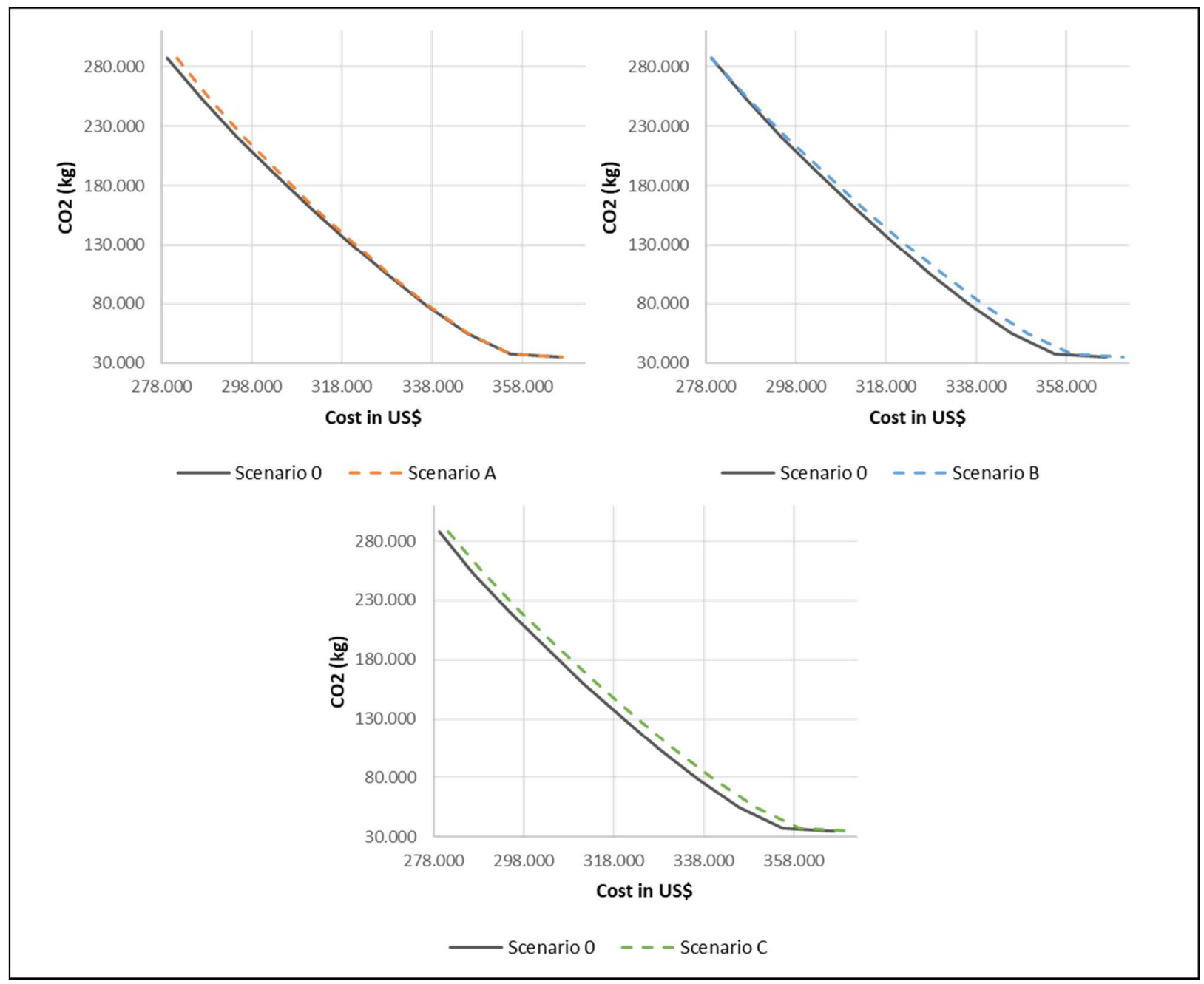

Fig. 12. Efficient frontiers of the sensitivity analysis

Table 10. Percentage of electric fleet and $\alpha$ values per scenario

\begin{tabular}{ccccc}
\hline $\begin{array}{c}\text { \% of electric } \\
\text { vehicles }\end{array}$ & Scenario 0 & Scenario A & Scenario B & Scenario C \\
\hline $0 \%$ & 1.00 & 1.00 & 1.00 & 1.00 \\
$10 \%$ & 0.97 & 0.97 & 0.97 & 0.97 \\
$20 \%$ & 0.97 & 0.97 & 0.97 & 0.97 \\
$30 \%$ & 0.97 & 0.97 & 0.97 & 0.97 \\
$40 \%$ & 0.97 & 0.97 & 0.96 & 0.97 \\
$50 \%$ & 0.96 & 0.97 & 0.96 & 0.96 \\
$60 \%$ & 0.96 & 0.96 & 0.96 & 0.96 \\
$70 \%$ & 0.96 & 0.96 & 0.97 & 0.96 \\
$80 \%$ & 0.95 & 0.95 & 0.95 & 0.95 \\
& & 26 & & \\
\end{tabular}




\begin{tabular}{ccccc}
$90 \%$ & 0.90 & 0.90 & 0.90 & 0.90 \\
$100 \%$ & 0.00 & 0.00 & 0.00 & 0.00 \\
\hline
\end{tabular}

\section{Conclusions and perspectives}

This paper evaluates the usage of electric vehicles in urban freight transport collaborative networks. The idea of using electric cars for freight transportation within a city emerges as a solution to reduce carbon emissions, traffic and noise contamination in downtown. Several aspects were taken into account to fully evaluate the transport operation in short- and mid-term scenarios, from both economic and environmental perspectives. Purchasing and maintenance vehicles costs and the cost of used energy (i.e. electricity or gasoline) were considered as economic costs. On the other hand, $\mathrm{CO}_{2}$ emissions by the production of the energy (i.e. electricity or gasoline) and the emissions by the energy consumption during transportation were selected as environmental components.

The approach presented in this paper considers the problems of collaborative network definition (i.e. costumers' allocation and routing process) and the use of different types of vehicles (i.e. electrics or gasoline), both in an integrated way. The objective was to evaluate the impact of implementing horizontal collaboration with a mixed fleet of (gasoline-based and electric) vehicles in terms of efficiency and effectiveness of the decision-making process. Since the problem of route distribution planning is highly complex in terms of computational resources, this problem was solved using a biased randomization-based optimization approach in order to improve the search process of near-optimal solutions for costumer's allocation and routing. Then, a multi-objective procedure is executed to create a relativized efficient frontier.

Computational tests were carried out using real data from the three major networks of convenience stores operating in Bogotá, Colombia. Firstly, our approach was compared against a heuristic method already available in the literature. According to the obtained results, our procedure seems to perform quite well and was able to outperform the heuristic method of Muñoz-Villamizar et al. (2017). This improvement occurs in phase 2 (customer allocation and routing sub-problems), in the biased randomized algorithm. Then, experiments of 1 and 5 years were performed to find an efficient frontier solution in the using of electric vehicles for short- and mid-term, respectively.

As a managerial conclusion, our findings suggest that the purchase of new vehicles (electric or gasoline) depends on the time horizon left for the operation. This is, electric vehicles are more profitable, both economically and environmentally, for periods of more than 3 years. Moreover, gasoline vehicles performs better for a short-time operation because of their lower purchasing cost. Finally, we can state that the economic savings for using gasoline vehicles are much relative lower than the reduction of the environmental impact by using electric vehicles. In the best of the cases, reductions up to $22 \%$ in environmental impact can be generated with economic overruns of only $2 \%$ in operational costs.

It is to note that, as this is a case-study based research, numerical results are valid for the case 
study. However, since a sensitivity analysis was also carried out, freight distribution companies in countries employing a similar mix of energy sources could find this results interesting to evaluate their own strategies. Another limitation of this work is that only one type of vehicle was selected to carry out the numerical experiments. This vehicle type was selected because of its market availability as both gasoline-base and electric technologies, so allowing a fair comparison of results. Despite this particular vehicle selection, the conceptual approach to solve the proposed problem is generic. Thus, numerical values can be easily changed as parameters of the algorithms so this study can be easily replicated anywhere else.

For further research, interesting opportunities emerge when other objective functions regarding environmental or social impact evaluations are considered. In fact, other economic costs (e.g. costs for depot adequacy or costs of fleet reassignment) can be used for a better understanding of the complex distribution operations in collaborative networks. Likewise, it is important to incorporate the life cycle environmental cost of electric vehicles by including the energy use and emissions associated with the components and parts production of this kind of vehicles. Finally, regarding the collaborative structure of distribution network, a variety of issues still prevent a widespread application of horizontal collaboration between companies in supply chains. The development of this type of collaboration requires the existence of a high level of trust among companies, being most of them reluctant to share information because they are usually competitors (Özener and Ergun. 2008). Another key issue when promoting horizontal collaboration practices is that the costs saving associated with collaborative strategies cannot be easily estimated for a single company but they have to be estimated on a global supply chain level. Hence, valuable opportunities for future research emerge in this area.

\section{Acknowledgments}

This work has been partially supported by the Spanish Ministry of Economy and Competitiveness (TRA2013-48180-C3-P and TRA2015-71883-REDT) and the Ibero-American Program for Science and Technology for Development (CYTED2014-515RT0489). Likewise, we want to acknowledge the support received by the Special Patrimonial Fund from Universidad de La Sabana (Colombia) and the doctoral grant from the UOC.

\section{References}

Adenso-Díaz, B., García-Carbajal, S., Lozano, S. (2012). A GRASP Algorithm for the Routes Conjoint Planning in Horizontal Cooperation Scenarios. Proceedings of the Eighth Spanish Meeting on Metaheuristics, Evolutionary and Bio- inspired Algorithms, pp. 561-566. Albacete, Spain.

Anand, G., Bahinipati, B.K. (2012) Measuring Horizontal Collaboration Intensity in Supply Chain: A Graph Theoretic Approach. Production Planning \& Control, 23, 801-816.

Arslan, O., Yildiz, B., Karasan, O.E. (2015) Minimum cost path problem for Plug-in Hybrid Electric Vehicles, Transportation Research Part E: Logistics and Transportation Review, 80, 123-141. 
Audatex. Costos de Mantenimiento. Available at: http://www.audatex.es/audaMantenimientosFeatures. Last accessed: 11 July 2017. (In Spanish) http://www.coches.net/servicios/costes-mantenimiento/renault/

Bahinipati, B.K., Kanda, A., Deshmukh, S.G. (2009) Horizontal collaboration in semiconductor manufacturing industry supply chain: An evaluation of collaboration intensity index. Computers \& Industrial Engineering, 57, 880-895.

Bailey, E., Unnikrishnan, A., Lin, D.-Y. (2011) Models for Minimizing Backhaul Costs through Freight Collaboration. Transportation Research Record: Journal of the Transportation Research Board, 2224, 51-60.

Bektaş, T., Demir, E., Laporte, G. (2016) Green vehicle routing. In: Green Transportation Logistics. Springer, pp. 243-265.

Bektas, T., Laporte, G. (2011) The pollution-routing problem, Transportation Research Part B: Methodological, 45, 1232-1250.

Braekers, K., Ramaekers, K., Van Nieuwenhuyse, I. (2016) The vehicle routing problem: State of the art classification and review. Computers \& Industrial Engineering, 99, 300-313.

Caputo, M., Mininno, V. (1996) Internal, Vertical and Horizontal Logistics Integration in Italian Grocery Distribution. International Journal of Physical Distribution and Logistics Management, 26 (9), 64-89.

Clarke, G., Wright, J. (1964) Scheduling of Vehicles from a Central Depot to a Number of Delivery Points. Operations Research. 12, 568-581.

Cirovic, G., Pamucar, D., Boanic, D. (2014) Green logistic vehicle routing problem: routing light delivery vehicles in urban areas using a neuro-fuzzy model, Expert Systems with Applications, 41, 4245-4258.

City Mayors. The largest cities in the world and their mayors. Available at: http://www.citymayors.com/statistics/largest-cities-mayors-1.html. Last accessed: 11 July 2017.

CODENSA. Tarifas. Available at: https://www.codensa.com.co/document/Tarifario_junio_2016.pdf. Last accessed: 11 July 2017. (In Spanish)

Comisión de Regulación de Energía y Gas (CREG). El Mercado Eléctrico Colombiano. Available

at: http://www.creg.gov.co/images/contenidos_estaticos/documentos/mercado_electrico_colombi ano.pdf. Last accessed: 11 July 2017. (In Spanish)

Cruijssen, F. (2006) Horizontal cooperation in transport and logistics. Tilburg University, Faculty of Economics and Business Administration. Tilburg: Tilburg University.

Cruijssen, F., Braysy, O., Dullaert, W., Fleuren, H., Salomon, M. (2007a). Joint route planning under varying market conditions. International Journal of Physical Distribution \& Logistics Management, 37 (4), 287-304.

Cruijssen, F., Cools, M., Dullaert, W. (2007b) Horizontal cooperation in logistics: Opportunities and impediments. Transportation Research Part E: Logistics and Transportation Review, 46(3), 22-39.

Cruijssen, F., Borm, P., Fleuren, H., Hamers, H. (2010) Supplier-initiated outsourcing: A methodology to exploit synergy in transportation. European Journal of Operational Research, 207, 763-774.

Cruijssen F, Salomon M (2004) Empirical study: order sharing between transportation companies 
may result in cost reductions between 5 to 15 percent. Center Research Institute, Tilburg University, discussion paper, September 2004

Dantzig, G.B., Ramser, J.H. (1959) The truck dispatching problem. Management Science 6(1), 80-91.

Demir, E., Bektas, T., Laporte, G., (2014a), The bi-objective pollution-routing problem, European Journal of Operational Research, 232(3): 464-478.

Demir, E., Bektas, T., Laporte, G. (2014b) A review of recent research on green road freight transporation. European Journal of Operational Research, 237 (3), 775-793.

Erdogan, S., Miller-Hook, E. (2012) A green vehicle routing problem. Transportation Research Part E: Logistics and Transportation Review, 48 (1), 100-114.

Ergun, O., Kuyzu, G., Savelsbergh, M. (2007) Reducing truckload transportation costs through collaboration. Transportation Science, 41(2), 206-221.

European Commission (2011a). EU transport in figures. Tech. Rept. Publications Office of the European Union. Available online at: http://ec.europa.eu/transport/factsfundings/statistics/doc/2011/pocketbook2011.pdf. $\quad$ Last access: 28 November 2017.

European Commission (2011b). Impact Assessment. Accompanying document to the white paper Roadmap to a Single European Transport Area - Towards a competitive and resource efficient transport system. Working Paper. European Commission

European Commission (2011c) EUR-Lex Access to European Union law. Available at http://eurlex.europa.eu/legal-content/EN/TXT/?uri=URISERV:126062 (Last access 28 November 2016)

European Union (2001). Guidelines on the Applicability of Article 81 of the AC Treaty to Horizontal. Cooperation Agreements. European Commission Notice 2001/C 3/02.

Felipe, A., Ortuno, M., Righini, G., Tirado, G. (2014) A heuristic approach for the green vehicle routing problem with multiple technologies and partial recharges. Transportation Research Part E: Logistics and Transportation Review, 71, 111-128.

Feng, W., Figliozzi, M. (2012) An Economic and Technological Analysis of the Key Factors Affecting the Competitiveness of Electric Commercial Vehicles. Transportation Research Part C, 26, 135-145.

Franceschetti, A., Honhon, D., Woensel, T.V., Bektas, T., Laporte, G. (2013) The timedependent pollution-routing problem, Transportation Research Part B: Methodological, 56, 265-293.

GlobalPetrolPrices.com. Gasoline prices. Available at: http://www.globalpetrolprices.com/gasoline_prices/. Last accessed: 11 July 2017.

Goeke, D., Schneider, M. (2015) Routing a mixed fleet of electric and conventional vehicles, European Journal of Operational Research, 245(1), 81-99

Gonzalez-Feliu, J., Morana, J. (2011) Collaborative transportation sharing: from theory to practice via a case study from France. In: J. Yearwood, A. Stranieri (eds.), Technologies for Supporting Reasoning Communities and Collaborative Decision Making: Cooperative Approaches, Information Science Reference, Hershey, PA, USA, 252-271.

Gonzalez-Feliu J., Morana J., Grau J.M.S., Ma T.Y. (2013). Design and scenario assessment for collaborative logistics and freight transport systems. International Journal of Transport Economics, 40 (2), 207-240. 
Hernández, S., Peeta, S., Kalafatas, G. (2011) A less-than-truckload carrier collaboration planning problem under dynamic capacities. Transportation Research Part E: Logistics and Transportation Review, 47(6), 933-946.

Hill, N., Brannigan, C., Smokers, R., Schroten, A., Van Essen, H., Skinner, I. (2012) EU transport GHG: routes to 2050 II. The role of GHG emissions from infrastructure construction, vehicle manufacturing, and ELVs in overall transport sector emissions. Available at: http://www.eutransportghg2050.eu/cms/assets/Uploads/Reports/EU-Transport-GHG-2050-IITask-2-FINAL-30Apr12.pdf (Last access 11 January 2018)

Jabir, E., Panicker, Vinay, V., Sridharan, R. (2015). Multi-objective Optimization Model for a Green Vehicle Routing Problem. Procedia - Social and Behavioral Sciences, 189, 15, 33-39.

Jovanović, A.D., Pamučar, D.S., Pejčić-Tarle, S. (2014). Green vehicle routing in urban zones A neuro-fuzzy approach. Expert Systems with Applications, 41 (7), 3189-3203.

Juan, A., Faulin, J., Jorba, J., Riera, D., Masip, D., Barrios, B. (2011) On the use of Monte Carlo simulation, cache and splitting techniques to improve the Clarke and Wright saving heuristics. Journal of the Operational Research Society 62(6), 1085-1097.

Juan, A.A. Mendez, C.A., Faulin, J., de Armas, J., Grasman, S.E. (2016) Electric Vehicles in Logistics and Transportation: A Survey on Emerging Environmental, Strategic, and Operational Challenges. Energies, 9, 86.

Koç, Ç., Bektaş, T., Jabali, O., Laporte, G. (2016) Thirty years of heterogeneous vehicle routing. European Journal of Operational Research, 249 (1), 1-21.

Krajewska, M., Kopfer, H., Laporte, G., Ropke, S., Zaccour, G. (2008) Horizontal Cooperation of Freight Carriers: Request Allocation and Profit Sharing. Journal of the Operational Research Society, 59, 1483-1491.

Lambert, D.M., Emmelhainz, M.A., Gardner, J.T. (1999) Building successful logistics partnerships. Journal of Business Logistics, 20 (1), 165-182.

Leitner, R., Meizer, F., Prochazka, M., Sihn, W. (2011) Structural concepts for horizontal cooperation to increase efficiency in logistics. CIRP Journal of Manufacturing Science and Technology, 4, 332-337.

Lera-López, F., Faulin, J., Sánchez, M. (2012). Determinants of the Willingness-to-Pay for Reducing the Environmental Impacts of Road Transportation. Transportation Research Part D, 17 (3), 215-220.

Lin, C., Choy, K.L., Ho, G.T., Chung, S., Lam, H. (2014). Survey of green vehicle routing problems: Past and future trends. Expert Systems with Applications, 41 (4), 1118-1138.

Lourenço, H.R., Martin, O., Stützle, T. (2010) Iterated local search: framework and applications. In: Handbook of Metaheuristics, edited by Gendreau, M., Potvin, J.-Y., 363-397. New York: Springer.

Madankumar, S., Rajendran, C. (2015). Mathematical models for green vehicle routing problems with pickup and delivery: A case of semiconductor supply chain. Computers and Operations Research, . Article in Press

Montoya-Torres J.R., Ortiz-Vargas D.A. (2014) Collaboration and information sharing in dyadic supply chains: A literature review over the period 2000-2012. Estudios Gerenciales, 30 (133), 343-354.

Montoya-Torres, J.R., López Franco, J., Nieto Isaza, S., Felizzola Jiménez, H., Herazo-Padilla, N. (2015) A literature review on the vehicle routing problem with multiple depots. Computers \& Industrial Engineering, 79, 115-129. 
Montoya-Torres, J.R., Muñoz-Villamizar, A., Vega-Mejía, C.A. (2016) On the impact of collaborative strategies for goods delivery in city logistics. Production Planning \& Control, 27 (6), 443-455.

Moons, S., Ramaekers, K., Caris, A. Arda, Y. (2016) Integrating production scheduling and vehicle routing decisions at the operational decision level: A review and discussion. Computers \& Industrial Engineering, In Press, DOI: j.cie.2016.12.010.

Moore T., Pulidindi J. (2013) Understanding urban transportation systems: an action guide for city leaders. National League of Cities. Available online at: www.nlc.org. Accessed 05 October 2017.

Muñoz-Villamizar, A., Montoya-Torres, J.R, Faulin J, (2017) Impact of the use of electric vehicles in collaborative urban transport networks: A case study. Transportation Research Part D, 50, 40-54.

Muñoz-Villamizar, A., J. R. Montoya-Torres, A. A. Juan, and J. Cáceres-Cruz. 2013. A Simulation-based Algorithm for the Integrated Location and Routing Problem in Urban Logistics. Proceedings of the 2013 Winter Simulation Conference (WSC 2013), edited by R. Pasupathy, S.-H. Kim, A. Tolk, R. Hill, and M. E. Kuhl, 2032-2041. Piscataway, NJ: IEEE.

Muñoz-Villamizar, A., Montoya-Torres, J.R, Vega-Mejia, C. (2015) Non-Collaborative versus Collaborative Last-Mile Delivery in Urban Systems with Stochastic Demands, Procedia CIRP, 30, 263-268.

Nadarajah, S. (2008) Collaborative Logistics in Vehicle Routing. University of Waterloo. Ontario, Canada

Nejat, P., Jomehzadeh, F., Taheri, M.M., Gohari, M., Majid, M.Z.A. (2015) A global review of energy consumption, $\mathrm{CO} 2$ emissions and policy in the residential sector (with an overview of the top ten CO2 emitting countries). Renewable and Sustainable Energy Reviews, 43, 843862.

Next Greencar ${ }^{\mathrm{TM}}$. RENAULT Kangoo Van Z.E. Available at: http://www.nextgreencar.com/view-car/31454/renault-kangoo--van-z.e.-electric-(av-ukmix)/\#compare-models. Last accessed: 13 July 2017.

Özener, O.O., Ergun, Ö. (2008) Allocating costs in a collaborative transportation procurement network. Transportation Science, 42 (2), 146-165.

Pérez-Bernabeu, E., Juan, A.A., Faulin, J., Barrios, B.B. (2015) Horizontal cooperation in road transportation: a case illustrating savings in distance and greenhouse gas emissions. International Transactions in Operational Research, 22, 585-606.

Prakahs, A., Deshmukh, S.G. (2010) Horizontal Collaboration in Flexible Supply Chains: A Simulation Study. Journal of Studies on Manufacturing, 1 (1), 54-58.

Punte, S. (2011) United Nations Centre for Regional Development. Available at http://www.uncrd.or.jp/content/documents/6EST-5A01.pdf (Last access 17 November 2017).

Quintero-Araujo, C.L., Gruler, A., Juan A.A., (2016) Quantifying Potential Benefits of Horizontal Cooperation in Urban Transportation Under Uncertainty: A Simheuristic Approach. In: Luaces O. et al. (eds) Advances in Artificial Intelligence. CAEPIA 2016. Lecture Notes in Computer Science, 9868, Springer, Cham.

Quintero-Araújo, C. L., Gruler, A., Juan, A. A. and Faulin, J. (2017a), Using horizontal cooperation concepts in integrated routing and facility-location decisions. Intl. Trans. in Op. Res.. doi:10.1111/itor.12479 
Quintero-Araújo, C.L., Montoya-Torres, J.R., Juan, A.A., Muñoz-Villamizar, A. (2017b). A Simheuristic Algorithm for Horizontal Cooperation in Urban Distribution: Application to a Case Study in Colombia. Proceedings of the 2016 Winter Simulation Conference (WSC 2016), T. M. K. Roeder, P. I. Frazier, R. Szechtman, E. Zhou, T. Huschka, and S. E. Chick (Eds.). 2193-2204.

Renault Colombia. https://www.renault.com.co. Last accessed: 13 July 2017.

Resende, M.G.C., Ribeiro, C.C. (2003). GRASP: greedy randomized adaptive search procedures. In Glover, F., Kochenberger, G. (eds) Handbook of Metaheuristics. Springer, Boston, MA, pp. 219-249.

Schneider, M., Stenger, A., Goeke, D. (2014) The electric vehicle-routing problem with time windows and recharging stations, Transportation Science, 48: 500-520.

Silva, I., Katz-Gerro, T. (2016). "Urban public transport companies and strategies to promote sustainable consumption practices". Journal of Cleaner Production, 123, 1 June 2016, 28-33. http://dx.doi.org/10.1016/j.jclepro.2015.12.007.

Talbi, E.-G. (2009). Metaheuristics: From Design to Implementation. Wiley Publishing.Toth, P., Vigo, D. (2014). Vehicle Routing: Problems, Methods, and Applications. SIAM - Society for Industrial and Applied Mathematics; 2nd Revised edition. Philadelphia. USA

Toth, P. and Vigo, D. (2014): Vehicle Routing: Problems, Methods, and Applications. MOSSIAM Series on Optimization. Philadelphia, PA.

Tsao, Y.-C., Lu, J.-C. (2012). A supply chain network design considering transportation cost discounts. Transportation Research Part E: Logistics and Transportation Review, 48(2), 401414.

Unidad de Planeación Minero Energética (UPME). Calculadora de Emisiones. Available at: http://www.upme.gov.co/Calculadora_Emisiones/aplicacion/calculadora.html. Last access: 11 July 2017. (In Spanish)

United Nations. (2011). Statistical Yearbook for Asia and the Pacific 2011. Available at http://www.unescap.org/stat/data/syb2011/escap-syb2011.pdf (Last access 22 October 2017)

van Lier, T., Caris, A., Macharis, C. (2016) Sustainability SI: Bundling of Outbound Freight Flows: Analyzing the Potential of Internal Horizontal Collaboration to Improve Sustainability. Networks and Spatial Economics, 16(1), 277-302.

Vanovermeire, C., Sörensen, K. (2014) Integration of the cost allocation in the optimization of collaborative bundling. Transportation Research Part E: Logistics and Transportation Review, $72,125-143$.

Verdonck, L., Caris., A, Ramaekers, K., Janssens, G.K. (2013) Collaborative logistics from the perspective of road transportation companies. Transport Reviews 33(6), 700-719.

Vornhusen, B., Kopfer, H. (2015) Emission Vehicle Routing Problem with Split Delivery and a Heterogeneous Vehicle Fleet. En F. Corman, S. VoB, \& R. R. Negenborn (Ed.), Proceedings of the 6th International Conference in Computational Logistics, pp. 76-90. Delft: Springer.

Vornhusen, B., Wang, X., Kopfer, H. (2014). Vehicle routing under consideration of transshipment in horizontal coalitions of freight carriers. Procedia CIRP, 19, 117-122.

Wang, X., Kopfer, H. (2011) Increasing efficiency of freight carriers through collaborative transport planning: Chances and challenges. Proceedings of the 6th German-Russian Logistics and SCM Workshop, DR-LOG 2011; 11-14 May, 2011.

Yıldız, B., Arslan, O., Karasßan, O.E. (2015) A branch and price approach for routing and refueling station location model. European Journal of Operational Research, 248(3), 815, 826. 
Yin, R.K. (2017). Case Study Research and Applications: Design and Methods. Los Angeles, USA: SAGE Publications, Inc. 6th Edition. 